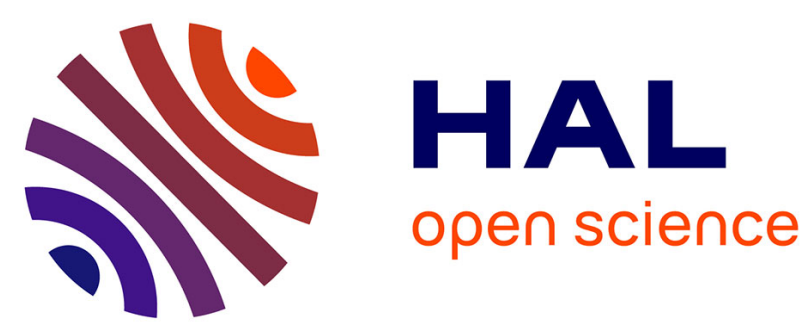

\title{
Characterization of newly developed expressed sequence tag-derived microsatellite markers revealed low genetic diversity within and low connectivity between European Saccharina latissima populations
}

\author{
Jaromir Guzinski, Stéphane Mauger, J. Mark Cock, Myriam Valero
}

\section{To cite this version:}

Jaromir Guzinski, Stéphane Mauger, J. Mark Cock, Myriam Valero. Characterization of newly developed expressed sequence tag-derived microsatellite markers revealed low genetic diversity within and low connectivity between European Saccharina latissima populations. Journal of Applied Phycology, 2016, 28 (5), pp.3057-3070. 10.1007/s10811-016-0806-7 . hal-01297556

\section{HAL Id: hal-01297556 \\ https: / hal.sorbonne-universite.fr/hal-01297556}

Submitted on 4 Apr 2016

HAL is a multi-disciplinary open access archive for the deposit and dissemination of scientific research documents, whether they are published or not. The documents may come from teaching and research institutions in France or abroad, or from public or private research centers.
L'archive ouverte pluridisciplinaire HAL, est destinée au dépôt et à la diffusion de documents scientifiques de niveau recherche, publiés ou non, émanant des établissements d'enseignement et de recherche français ou étrangers, des laboratoires publics ou privés. 
Characterization of newly developed expressed sequence tag-derived microsatellite markers revealed low genetic diversity within and low connectivity between European Saccharina latissima populations

Jaromir Guzinski ${ }^{1,3}$, Stéphane Mauger ${ }^{1}$, J. Mark Cock $^{2}$, Myriam Valero ${ }^{1}$

${ }^{1}$ CNRS, UPMC, Sorbonne Universités, PUCCH, UACH, UMI 3614, Evolutionary Biology and Evolution of Algae, Station Biologique de Roscoff, Place Georges Teissier, CS 90074 Roscoff, France

${ }^{2}$ CNRS, UPMC, Sorbonne Universités, UMR8227, Laboratoire Végétaux Marins et Biomolécules, Équipe Génétique des Algues, Station Biologique de Roscoff, Place Georges Teissier, CS 90074 Roscoff, France

${ }^{3}$ CNRS, UPMC, Sorbonne Universités, UMR7144, Adaptation et diversité en Milieu Marin, Équipe Diversité et Connectivité dans le Paysage Marin Côtier, Station Biologique de Roscoff, Place Georges Teissier, CS 90074 Roscoff, France

\section{Abstract}

The kelp Saccharina latissima is a species of high ecological and economic importance. We developed a novel set of $S$. latissima-specific genetic markers that will find applications in conservation biology, biodiversity assessment, and commercial exploitation of this macroalga. Thirty two expressed sequence tag (EST)-derived microsatellite markers (SSRs) were developed and characterized in this study using publically available EST sequences. Twenty seven percent of the 7,064 analysed ESTs contained repeat motifs, and polymerase chain reaction (PCR) amplification primers were designed for 96 selected loci. Fifty one (53\%) of the primer pairs amplified their target loci, of which 32 (33\%) were polymorphic within a sample of $96 \mathrm{~S}$. latissima sporophytes collected from six localities distributed along the European Atlantic coast from Southern Brittany (France) to Spitzbergen (Norway). The 32 loci harboured moderate levels of polymorphism with 2-13 alleles per locus (mean 
5.4). The 25 loci that were retained for population genetic analyses revealed substantial genetic differentiation among the European populations (pairwise $F_{S T}$ values ranging from 0.077 to 0.562 ) that did not follow any pattern of isolation by distance. In addition, within-population genetic diversity was generally low $(H s<0.323)$. Two non-mutually exclusive hypotheses were proposed to explain this low diversity pattern: (1) lower variability of the EST-derived microsatellites compared to the random distribution of SSRs developed from genomic DNA since the former are frequently located in coding regions, which are generally less variable, or (2) reduced effective population size of S. latissima. The particularly high genetic differentiation between the French and Scandinavian S. latissima populations is in agreement with the reported ecotypic differentiation, which may reflect an important resource for genetic improvement. The pattern of genetic diversity revealed in this study thus suggests that care should be taken to avoid the transfer of strains between different geographic regions.

Keywords: Saccharina latissima, Phaeophyceae, NE Atlantic, EST, population genetic structure, simple sequence repeat

\section{Introduction}

Saccharina latissima (Linnaeus), known by the common names of sea belt or sugar kelp, is a perennial brown macroalga (class Phaeophyceae), of the family Laminariaceae. This species exhibits circumpolar distribution in the northern hemisphere, occurring in polar and temperate coastal waters from intertidal to a lower depth limit of about 30 meters (Bolton et al. 1983; Gerard 1988). S. latissima forms continuous dense stands ("kelp forests") on shallow rocky coasts, occurring in clear and turbid waters, preferentially in areas sheltered from strong wave action (Bekby and Moy 2011). In Europe, its range extends from Spitsbergen, Norway as far south as Portugal. S. latissima requires rocky substrate as an attachment point and does not occur where this surface is replaced by long stretches of sandy coast (Bartsch et al. 2008). Both the wide latitudinal and vertical distribution of 
this species suggest the occurrence of ecotypic differentiation between populations with respect to light and temperature (Gerard and Du Bois 1988; Müller et al. 2008). However, knowledge about genetic diversity and connectivity is still lacking and this information will be important not only for elucidating population structure across the range of S. latissima but also for improved exploration of genetic resources in the wild.

In general, the dispersal capacities of macroalgae are limited, on the order of few meters up to several kilometres, compared with distances of hundreds of meters to several hundred kilometres for other marine organisms such as invertebrates or fish characterized by a pelagic larval dispersal phase (Kinlan and Gaines 2003). In kelps, dispersal is primarily mediated by short lived propagules, and the extent of dispersal depends on factors such as the morphology of the blade (i.e. location of the sporophylls on the thallus and whether they possess swimming aids such as air bladders, see Valero et al. 2011 for a review), as well as on the orientation of currents and habitat continuity (Billot et al. 2003; Alberto et al. 2010; Coleman et al. 2011). In a recent meta-analysis of genetic differentiation in macroalgae, Durrant et al. (2014) found that most species exhibited a clear pattern of isolation by distance with high level genetic differentiation at distances greater than $50-100 \mathrm{~km}$. However, occasional long distance dispersal, even on the scale of tens to hundreds of kilometres, can occur due to pieces of fertile thalli breaking off and being carried away from the point of origin by currents (Thiel and Gutow 2005; Alberto et al. 2011; Coleman et al. 2011). Additionally, Cie and Edwards (2011) have uncovered a mechanism facilitating vertical transport of kelp zoospores into the shallower portions of the water column, which has been proposed to enable long distance dispersal of zoospores via current action. Indeed, it has recently been suggested that spore dispersal is not likely to be a limiting factor in maintaining connectivity between Norwegian S. latissima populations (Andersen 2013). Therefore, it remains an open question as to whether S. latissima populations are genetically distinct (limited dispersal - spores recruiting within their population of origin), or whether there is some degree of genetic homogenization and thus lack of pronounced spatial or geographic structure (long distance dispersal, even if only occasional, resulting in a certain number of spores 
recruiting to distant populations). Until now this question has not been investigated, largely because the necessary genetic tools have been lacking.

As a primary producer, S. latissima plays a crucial role in the functioning of the subtidal ecosystem and dense S. latissima stands provide a habitat for a plethora of marine organisms (Bekby and Moy 2011). Additionally, this is a species of high economic importance, with applications in the food, bioenergy, cosmetic and pharmaceutical industries. S. latissima is considered to be a species of choice for the production of brown seaweed biomass in Europe (Peteiro 2013) because it has a shorter life cycle than those of L. digitata and Laminaria hyperborea, the other two most abundant kelps along the European coast. Furthermore, S. latissima is closely related to Saccharina japonica, a domesticated species that occurs along the north-western coasts of the Pacific Ocean. Indeed, $S$. japonica is one of the most economically important types of seaweed in the seaweed farming industry with a long history of breeding programs and artificial seedling-rearing techniques (Tseng 2001). The complete genome of $S$. japonica has been recently published providing a vital resource for algal genome studies and improvement of traits of economic importance (Ye et al. 2015). For these reasons S. latissima is a good model species for studying algal domestication in Europe, and, as a likely commercially important species, it is about to become a subject of studies aimed at identifying strains exhibiting traits of interest for cultivation.

Given the significant ecological and commercial importance of S. latissima, it is of particular concern that over the past five to 10 years this species has experienced large scale population declines at sites in Norway, where $50 \%$ of Europe's S. latissima forests are found, as well as in Sweden and Germany (Bekby and Moy 2011). It is therefore urgent to develop a set of speciesspecific genetic markers that could be employed to elucidate and monitor S. latissima population structure and hence provide guidance on how to best implement conservation and management strategies.

Microsatellites, also known as simple sequence repeats (SSRs), are among the most commonly used marker types in evolutionary and ecological studies. SSRs are appropriate for the 
determination of genetic diversity because they are abundant in the genome, are highly polymorphic, are highly reliable, and usually have a codominant mode of inheritance. The development of microsatellites has traditionally involved a large input of time and labour for the construction, enrichment and sequencing of genomic libraries (Edwards et al. 1996). In contrast, identification of SSRs from expressed sequences (EST-SSRs) is a fast, efficient and relatively low cost alternative (Bouck and Vision 2007). EST-SSRs facilitate physical mapping and tend to be widely transferable between species and even between genera (Liu et al. 2012). Here we describe the development of a suite of EST-based (Heinrich et al. 2012), S. latissima-specific microsatellite markers. Additionally, we test the ability of these newly developed SSRs to differentiate between individuals from six natural populations of S. latissima distributed from Brittany to Norway and investigate the importance of inter-population connectivity. We also discuss the potential uses of these markers for applied research (conservation, strain selection) on this kelp species.

\section{Material and Methods}

\section{Sample collection and DNA extraction}

Sixteen mature S. latissima sporophytes were collected from each of six sampling locations. The six sites, SB - Mousterlin, France, NB - Roscoff, France, PDC - Audresselles, France, DEN - Ebeltoft, Denmark, SWE - Tjarno, Sweden, and NOR - Ny-Alesund, Spitsbergen, Norway, followed a latitudinal gradient (Figure 1). Upon collection, a disk of tissue (diameter $2 \mathrm{~cm}$ ) was cut out from a spot that was free of epiphytes and stored with silica gel. If possible, the sample was taken from close to the junction of the stipe and the blade as the aim was to sample the youngest tissue.

Total genomic DNA was extracted from five to $10 \mathrm{mg}$ of dry tissue using the Nucleospin ${ }^{\circledR} 96$ plant kit (Macherey-Nagel, Düren, Germany). The extractions were performed according to the manufacturer's instructions except that samples were left in the lysis buffer at room temperature for one hour rather than being heated to $65^{\circ} \mathrm{C}$ for 30 minutes. The extracted DNA was eluted in $200 \mu \mathrm{L}$ of the supplied elution buffer. 
EST-SSR screening and primer design

133 A total of 400,503 S. latissima ESTs obtained from the Sequence Read Archive (SRA) database

134 (accession number: SRR305166 (Heinrich et al. 2012)) were screened for di-, tri-, tetra-, and pentanucleotide motif SSRs using the Sputnik program (http://espressosoftware.com/sputnik/). Seven thousand and sixty four ESTs were found to contain at least one SSR, with $438(6 \%)$ containing a dinucleotide repeat microsatellite, 2,330 (33\%) containing a trinucleotide repeat microsatellite, $1,765(25 \%)$ containing a tetranucleotide repeat microsatellite, and 2,531 (36 \%) containing a pentanucleotide repeat microsatellite (Table 1). For loci where the flanking sequence on either side of the repeat was of sufficient length, PCR amplification primers were designed in Primer3 (Rozen and Skaletsky 2000). In-house scripts were used to specify the primer selection conditions, which used default values for all parameters except the optimum melting temperature, which was set to 60 ${ }^{\circ} \mathrm{C}$ (range $57-62^{\circ} \mathrm{C}$ ) and the expected product size, which was set at $350 \mathrm{bp}$. \%) tri-, $428(22.8 \%)$ tetra-, and 331 (17.6\%) pentanucleotide repeat loci (Table 1). In order to costeffectively test these primers for amplification, and then check the amplified loci for levels of polymorphism within the sampled individuals, we reduced the number of loci used in the trials to 96 (i.e. capacity of a microtiter plate), employing the following criteria (see Table 1 for details). First, we eliminated all loci which contained an unknown base ("N") within the repeat region. Next, for the diand trinuclotide motif SSRs only those loci which comprised at least eight repeat units were retained, and for the tetra- and pentanucleotide motif SSRs only those loci which comprised at least five repeat units were retained (184 loci remaining - Table 1). Finally, the number of loci was reduced to 96 such that loci with the highest number of repeats were selected for each of the four motif categories. 

individuals, one individual from each locality. Amplifications were carried out in $10 \mu \mathrm{L}$ reaction volumes with each reaction comprising: $2 \mu$ l of DNA template diluted 1:50, 1x GoTaq ${ }^{\circledR}$ Flexi buffer (Promega Corporation), $2 \mathrm{mM} \mathrm{MgCl}, 150 \mu \mathrm{M}$ of each dNTP (Thermo Fisher Scientific Inc., Waltham, MA, USA), 30 pmol forward primer, 30 pmol reverse primer, 30 pmol fluorescent-labelled M13(-21) primer (Eurofins MWG Operon, Ebersberg, Germany) and 0.35 U GoTaq ${ }^{\circledR}$ Polymerase (Promega Corporation). The $5^{\prime}$ end of each forward primer included an M13 (-21) universal sequence tag (5'TGTAAAACGACGGCCAGT-3') to enable the incorporation of the universal fluorescent-labelled M13 (21) primer for detection of the amplified products on an ABI3130 XL DNA Analyser (Applied Biosystems, Foster City, CA, USA). The 96 loci were divided into four randomly selected groups (24 loci per group), and each of the four groups of loci was labelled with a different color. Amplifications were carried out in a BioRad DNA Engine Peltier Thermal Cycler under the following conditions: initial denaturation at $95^{\circ} \mathrm{C}$ for $5 \mathrm{~min}, 12$ cycles of denaturation at $95^{\circ} \mathrm{C}$ for $30 \mathrm{~s}$, annealing at $65^{\circ} \mathrm{C}$ for $30 \mathrm{~s}$ $\left(-1^{\circ} \mathrm{C} / \mathrm{cycle}\right.$ - touchdown until $\left.53^{\circ} \mathrm{C}\right)$, and extension at $72^{\circ} \mathrm{C}$ for $30 \mathrm{~s}$, and $30 \mathrm{cycles}$ of denaturation at $95^{\circ} \mathrm{C}$ for $30 \mathrm{~s}$, annealing at $53{ }^{\circ} \mathrm{C}$ (optimum M13 (-21) annealing temperature) for $30 \mathrm{~s}$, extension at $72{ }^{\circ} \mathrm{C}$ for $30 \mathrm{~s}$, followed by a final extension of $72{ }^{\circ} \mathrm{C}$ for $10 \mathrm{~min}$. The PCR products labelled with the four different colours were pooled ( 24 pools in total) and diluted 1:10 with water. Next, two $\mu \mathrm{L}$ of the diluted PCR product pool were added to $10 \mu \mathrm{L}$ of loading buffer made up of $0.5 \mu \mathrm{L}$ of the SM594 size standard (Mauger et al. 2012) and 9.5 $\mu \mathrm{L}$ of Hi-Di formamide, denatured at $95^{\circ} \mathrm{C}$ for three minutes, and run in an $\mathrm{ABI} 3130 \mathrm{XL}$ capillary sequencer (Applied Biosystems, Foster City, CA, USA). Genotypes were scored manually in Genemapper version 4.0 (Applied Biosystems, Foster City, CA, USA). Forty five of 96 primer pairs did not amplify a product from any of the six individuals despite several re-amplifications and were not further analysed. 
The 51 loci retained after the amplification tests were subsequently checked for levels of polymorphism within the sample of $96 \mathrm{~S}$. latissima individuals. Amplifications were carried out in same manner as described for the amplification trials.

Within the sample of $96 \mathrm{~S}$. latissima individuals, 36 of the 51 loci were polymorphic. However, two of the polymorphic loci failed to amplify in many of the individuals originating from NB, PDC, DEN, and SWE (Sacl-70 amplified in 76 out of 96 samples, and Sacl-77 in 72 samples). As reamplifications did not resolve this issue, these two loci were not retained for further analyses (see Supplementary Table 1 for the primer sequences and repeat motif details for these two loci, and Supplementary Table 2 for information on the 15 monomorphic loci). Two pairs of linked loci were detected among the remaining 34 loci (see Statistical analyses section) and, after removal of one locus from each pair, the remaining 32 loci were used for population genetics analyses.

\section{Multiplex development}

In order to optimize the usage of the 32 loci in future population genetics studies, we used Multiplex Manager v 1.2 (Holleley and Geerts 2009) with default parameters to organize the amplification of the loci in as few multiplex reactions as possible. Three multiplexes were created: multiplexes 1 and 2 comprised 10 loci each, and multiplex 3 comprised 12 loci (Table 2). For each multiplex, two disparate sets of loci were amplified separately to minimize primer dimer formation, but the two sets were pooled before genotyping. For multiplex 1 these were set M1i and set M1ii, whereas for multiplex 2 these were set M2i and set M2ii, and for multiplex 3 these were set M3i and set M3ii (Table 2). Each of the six multiplex sets was amplified in the same manner as described for the amplification trials, except that we added 40 pmol of each forward fluorescently-labelled primer (Eurofins MWG Operon, Ebersberg, Germany), 40 pmol of each reverse primer, and 0.5 U GoTaq ${ }^{\circledR}$ Polymerase. Amplifications were carried out in a BioRad DNA Engine Peltier Thermal Cycler under the following conditions: initial denaturation at $95^{\circ} \mathrm{C}$ for $5 \mathrm{~min}, 10$ cycles of denaturation at $95^{\circ} \mathrm{C}$ for 30 $\mathrm{s}$, annealing at $65^{\circ} \mathrm{C}$ for $30 \mathrm{~s}\left(-1{ }^{\circ} \mathrm{C} / \mathrm{cycle}\right.$ - touchdown to $\left.55^{\circ} \mathrm{C}\right)$, and extension at $72{ }^{\circ} \mathrm{C}$ for $30 \mathrm{~s}$, and 
30 cycles of denaturation at $95^{\circ} \mathrm{C}$ for $30 \mathrm{~s}$, annealing at $55^{\circ} \mathrm{C}$ for $30 \mathrm{~s}$, extension at $72{ }^{\circ} \mathrm{C}$ for $30 \mathrm{~s}$,

210 followed by a final extension of $72{ }^{\circ} \mathrm{C}$ for $10 \mathrm{~min}$.

\section{Statistical analyses}

213

214

We used Genepop v 4.3 (Rousset 2008) to test for linkage disequilibrium between all pairs of the 34 loci within each of the six sampling sites as well as for all localities combined (global test employing Fisher's method). This analysis used the following Markov chain parameters: dememorisation: 100,000; batches: 1,000; iterations per batch: 50,000. All significance levels were adjusted from an alpha value of 0.01 using sequential Bonferroni correction to allow for multiple tests on the same dataset (Rice 1989). We omitted locus Sacl-14 from further analyses since it exhibited significant linkage disequilibrium with locus Sacl-66 in three localities (NB, SB, DEN) and across all populations. We also omitted locus Sacl-72 since its allele patterns were identical to those of locus Sacl-08 (i.e. Sacl-72 alleles were always one base larger than Sacl-08 alleles) for all individuals with the exception of a genotype for a single NOR individual.

For each of the remaining 32 loci we calculated the following statistics using the combined sample of all 96 amplified individuals with the indicated R (R Development Core Team 2015) package. Number of alleles $\left(N_{A}\right)$ and the polymorphic information content $(\mathrm{PIC})$ were estimated in PopGenKit (Paquette 2012), whereas hierfstat (Goudet 2014) was used to obtain the observed heterozygosity $\left(H_{O}\right)$ and the overall gene diversity $\left(H_{T}\right)$ (Nei 1987). All significance levels were adjusted using sequential Bonferroni corrections (Rice 1989). Next, we computed for each of the 32 loci within each locality, allelic richness (Ar), $H_{O}$, and within-population gene diversity $\left(H_{S}\right)$ (Nei 1987) using hierfstat, with the per locus "All Pops" $\mathrm{Ar}$ and $H_{S}$ obtained by averaging these two parameters over the six localities. $F_{\text {IS }}$ values for each locus within each locality were calculated in Demerelate (Kraemer and Gerlach 2013). Significance for each estimate was obtained by generating 10,000 bootstraps. The "All Pops" $F_{I S}$ and $F_{S T}$ parameters were calculated in hierfstat. 
(Brookfield 1996). The equation was run for each of the genotyped loci, separately for each of the six sampling locations, using Micro-Checker 2.2.3 (Van Oosterhout et al. 2004). The confidence interval for the Monte Carlo simulations of the homozygote frequencies was set to $95 \%$.

Subsequent analyses were performed using a reduced set of 25 loci (after removing loci with null alleles and/or exhibiting odd allelic patterns, see Results and Supplementary Material 1). For each of the six localities, we estimated the mean $\mathrm{Ar}$ and mean $H_{s}$ by averaging over the 25 locus specific values presented in Supplementary Table 3 (for underlined loci only). The $H_{s}$ means were compared between the six populations using the Kruskal-Wallis test. $F_{I S}$ for each of the six populations was estimated as the multilocus estimate of Wright's inbreeding coefficient using diveRsity (Keenan et al. 2013). Significance was tested with 10,000 bootstrap iterations, and the values were considered to be significant if the bias-corrected $95 \%$ confidence intervals did not overlap zero. The global (i.e. over all loci and all populations) values for $H_{S}, F_{I S}$, and $F_{S T}$ were estimated by calculating the average of the over-population means (obtained from hierfstat) for each of these parameters over the 25 loci.

To estimate the level of genetic differentiation between the six sampling localities, pair-wise $F_{\text {ST }}$ (Weir and Cockerham 1984) values were computed in hierfstat. The significance of the comparisons was estimated by performing 10,000 bootstraps over loci, with the comparisons judged significant if the bootstrap generated confidence intervals that did not overlap zero.

To gain further insights into S. latissima population subdivisions across our sampling range, and in particular to determine if the six clusters defined based on the sampling localities reflect the biological reality, we used the Discriminant Analysis of Principal Components (DAPC) method implemented in the adegenet $\mathrm{R}$ package (Jombart 2008; Jombart et al. 2010). This multivariate statistical approach seeks to provide an efficient description of genetic substructure through the use of a limited number of synthetic variables called the discriminant functions. DAPC infers the number of clusters of genetically related individuals (i.e. the number of distinct populations) by partitioning 
the original variables (allele frequencies) into within-group and between-group components such that between-group variance is maximized. We used the six predefined clusters as the input for DAPC as the $F_{S T}$ analysis showed all pairwise comparisons to be significant (see Results). Finally, we tested for isolation by distance (IBD) between the six S. latissima populations. The geographic distance was the "as crow flies" direct distance in kilometres between each of the localities, whereas the genetic distance was Rousset's $F_{S T} /\left(1-F_{S T}\right)$ estimate for each pair of populations (Rousset 1997). The significance of the IBD relationship was tested statistically with a Mantel test in R package vegan (Oksanen et al. 2015) with 999 permutations.

\section{Results}

Of the 96 primer pairs selected for the amplification trials, amplification was successful for 51 loci (53 \%) (Supplementary Figure 1). Of these, two loci (Sacl-70 and Sacl-77) were removed due to inconsistent amplification in a larger sample of individuals, and two were dropped because they were found to be in linkage with other loci (Sacl-08 and Sacl-14). Of the 47 remaining EST-SSR loci, 32 loci (68\%) were polymorphic within the analysed sample of 96 S. latissima sporophytes originating from six disparate geographic locations (Figure 1). These 32 loci displayed variable levels of polymorphism, with PIC ranging from 0.010 to 0.823 with a mean of 0.350 , and 11 (34 \%) of the loci displaying values above 0.450 . The number of alleles per locus ranged from two to 13 while the average over 32 loci was 5.41 alleles per locus (Table 2). Observed heterozygosity $H_{O}$ was the highest at 0.875 for locus Sacl-49, whereas locus Sacl-27 was homozygous within all the scored individuals (Table 2). Mean $H_{O}$ was 0.253 and the average overall gene diversity $\left(H_{T}\right)$ was $0.385 . H_{O}$ was lower than $H_{T}$ at 24 of the 32 loci, probably because of a Wahlund effect due to pooling of individuals from multiple genetic clusters, but other contributing causes (inbreeding or the presence of null alleles) might also be involved. To minimize the possibility of the Wahlund effect, the per locus statistics were estimated within each of the six geographic localities (Supplementary Table 3). 
within the context of our dataset, and were thus removed from all subsequent analyses (details are

given in Supplementary Material 1 and in Supplementary Table 3). Briefly, these seven loci (Sacl-06,

Sacl-09, Sacl-27, Sacl-47, Sacl-49, Sacl-88, Sacl-90) were removed because they exhibited significant null allele frequency at multiple geographic localities, displayed low levels of polymorphism, or they exhibited odd allelic patterns with for instance fixed heterozygosities in some populations (highly removed were deemed unsuitable for our analyses, they could be of use for other types of studies or studies on other populations of S. latissima, thus they are also reported in this manuscript and were optimized as part of the multiplexes specified in Table 2. (Supplementary Table 3). Thus the within-population observed allelic richness averaged over the 25 loci was low, ranging from 2.080 in SWE to 2.840 in SB (Figure 2, Supplementary Table 3). The highest observed heterozygosity value was 0.938 for locus Sacl-38 within the NOR samples, while the lowest value (0.063) was observed within NB for five loci and within DEN for three loci (Supplementary Table 3). Similarly, the locus-specific, within-population gene diversity $\left(H_{s}\right)$ values were generally low. The multilocus within-population $H_{s}$ means ranged from 0.204 for PDC to 0.323 for NOR (Figure 2, localities (Kruskal-Wallis test $\mathrm{X}^{2}(5)=4.549, \mathrm{p}$-value $=0.473$ ), and thus did not vary with latitude. This was also the case for the Ar means (Figure 2). The within-population multilocus $F_{/ S}$ values were not significantly different from zero for any of the six geographic localities, which indicates that random mating commonly occurs within the studied populations. 
pattern of genetic differentiation among populations was highly significant with an overall $F_{S T}$ mean of 0.259 and 10 loci exhibiting $F_{S T}$ values above 0.300 (Supplementary Table 3).

All of the pairwise multilocus $F_{S T}$ comparisons were significant. The least differentiated populations were SB and NB, with $F_{S T}$ of 0.077 (Table 3). These populations exhibited approximately equal levels of divergence from PDC, with the geographically more distant SB being also slightly more distant genetically. The $F_{S T}$ between DEN and SWE was the second lowest at 0.120 , with both these populations being highly genetically differentiated from NOR ( $F_{S T}$ above 0.250 in both comparisons) (Table 3). The highest levels of differentiation were between the three north European populations and the three French populations, with $F_{S T}$ ranging from 0.358 to 0.562 (Table 3). The IBD model was rejected (Mantel statistic $r=0.275$, significance $=0.112$ ) (Figure 3 ), since the more geographically distant NOR population was less differentiated from the three French localities than the less distant DEN and SWE populations.

The DAPC results correlate well with the $F_{S T}$ estimates (Figure 4). Axis 1 (which explains $45.12 \%$ of the variance) separates the three French sampling localities from the three Scandinavian sampling sites (Figures $4 \mathrm{a}$ and $4 \mathrm{~b}$ ), while axis 2 (which explains $10.83 \%$ of the variance) separates NOR from the other five sampling localities (Figure 4a) and axis 3 (which explains $6.03 \%$ of the variance) partitions the French sampling site into a PDC and an SB/NB cluster (Figure 4b). Indeed, the two pairs of localities displaying the lowest pairwise $F_{S T}$ values (SB and NB, and DEN and SWE) were the least well defined by DAPC. There was no clear separation of these two pairs of sites within any of the first three principal components of the DAPC, as there was always some overlap between individuals from these two localities (Figures $4 a$ and $4 b$ ). The admixture plot (Figure 4c) however revealed that most of the SB/NB individuals were assigned to their population of origin, with only nine out of 32 individuals originating from the SB/NB localities exhibiting some level of admixture. The level of admixture between PDC and the SB/NB localities was even lower (Figure 4c). The admixture situation within the Scandinavia sampling localities mirrored that within the French sites, although the DEN/SWE admixture was less substantial in comparison to the SB/NB admixture (Figure 
4c). Finally, there was no evidence of admixture between the two sampling regions (i.e. France and Scandinavia, Figure 4c).

\section{Discussion}

Of the 96 primer pairs that were tested for amplification with six S. latissima sporophytes, 51 (53\%) were deemed successful (though subsequently two of these loci were dropped due to inconsistency of amplification within a larger sample of individuals) (Supplementary Figure 1). Our markers therefore exhibited a higher positive amplification rate than was reported by Wang et al. (2011) (36.5 \%) for Laminaria-specific EST-SSRs. For the loci presented herein, the success of amplification was poorest for loci comprising tetranucleotide motifs (31.3\%) and best for those comprising dinucleotide motifs ( $81.3 \%$ ), whereas it was just under $60 \%$ for loci comprising the trinucleotide and pentanucleotide motif types (Supplementary Figure 1). Utilization of expressed sequence tags to identify so called genic SSRs is a relatively recent approach, but one that has been successfully employed in a vast array of taxa (Ellis and Burke 2007). The main advantage over the traditional method of isolation of microsatellite markers (in this case termed genomic SSRs) is that obtaining SSRs from ESTs is considerably less labour intensive and also cheaper (Zane et al. 2002; Ellis and Burke 2007). In this study, there was a high attrition rate amongst the newly developed markers, with only around $50 \%$ of the amplification trials being successful, 33 $\%$ of markers being polymorphic, and just over a quarter of the markers ( 25 out of $96-26 \%$ ) being retained for the population genetics analyses. However, the time and effort spent on acquiring these markers was not excessive, and a reasonably high number of markers were obtained. The traditional method of isolating SSRs, partly due to the above mentioned difficulties, rarely results in more than 20 markers being produced. Indeed, 16 genomic SSRs have recently been developed for S. latissima (Møller Nielsen et al., submitted). Note that, as 184 loci were retained after the reduction step 
amplification and polymorphism so far, there is potential to develop additional S. latissima specific EST-SSRs from this analysis if needed.

A potential disadvantage of EST-SSRs as genetic markers is that they are commonly considered to harbour lower levels of polymorphism than genomic SSRs because they are derived from expressed, and thus conserved, genes (Gupta et al. 2003; Ellis and Burke 2007; Guichoux et al. 2011). However, various studies have demonstrated that the EST-derived SSRs were sufficiently diverse to be useful markers for population genetics analyses (Dong et al. 2009; Cubry et al. 2014; Teshome et al. 2015), and that conclusions regarding population structure and connectivity were highly congruent whether elucidated with genomic or EST-derived SSRs (Woodhead et al. 2005; Kim et al. 2008; Hu et al. 2011).

The number of alleles per locus we detected in our study ( 5.41 alleles per locus averaged over 32 loci) was higher than or comparable to the genomic or EST-SSR sets described in the literature. For example, in a closely related congener species S. japonica the average number of alleles over 18 genomic SSR loci was 4.7 alleles per locus (Shi et al. 2007), whereas on average 5.7 alleles per locus were obtained for nine EST-SSR loci (Liu et al. 2010).

To demonstrate the applicability of this newly developed set of S. latissima EST-SSR markers for effective management of this ecologically and economically important species, we investigated the patterns of within-population genetic diversity and connectivity between six localities spanning a latitudinal gradient from South Brittany, France to Spitsbergen, Norway using the reduced panel of 25 loci.

Our data indicate that the six studied populations were significantly genetically differentiated (significant $F_{S T}$, Table 3), and formed genetically well-defined clusters even if there was some degree of connectivity between the populations that were closest geographically (Figure 4). The clustering of the two Brittany populations (SB and NB) into two distinct but not completely isolated groups fits well with what was reported for two other kelps, L. digitata and L. hyperborea (Couceiro et al. 2013; Robuchon et al. 2014) in the same region. The Ushant tidal front, which constitutes a seasonal 
dispersal barrier, is probably one of the major factors that influence the observed pattern of kelp population structure in this region as discussed in Couceiro et al. (2013).

Further north along the French coast, the PDC sampled sporophytes exhibited substantially lower connectivity to the two Brittany localities than was detected within Brittany (i.e. between SB and NB) (Table 3, Figure 4). The pattern of isolation between the Breton sites and PDC is likely explained by habitat discontinuity as the shore line either side of the PDC sampling site is characterized by long stretches of sandy substrate. Lack of suitable (i.e. rocky) substrate has been proposed to be a major dispersal barrier for several other kelps (Fraser et al. 2010; Alberto et al. 2011; Couceiro et al. 2013, Robuchon et al. 2014). However, the status of PDC as a small, fragmented and/or isolated population cannot be fully established from our data given that the expected decrease in the within-population gene diversity $\left(H_{s}\right)$ and allelic richness $(\mathrm{Ar})$ compared to the supposedly larger and better connected populations (i.e. SB and NB) was not significant (Figure 2). Consequently, the genetic isolation of PDC from the Breton samples could simply be due to a combination of the distance between the two sites and the limited dispersal capabilities of $S$. latissima, and not necessarily be due to habitat discontinuity. On the other hand, as the $H_{s}$ and $\mathrm{Ar}$ estimates for the two Brittany sampling sites were particularly low, i.e. at least twice as low as those described for L. digitata (Billot et al. 2003; Couceiro et al. 2013; Robuchon et al. 2014) and L. hyperborea (Robuchon et al. 2014) sampled from nearby points along the Brittany coast, this could suggest that S. latissima populations are characterized by smaller population size in comparison to those of other kelps. Indeed, along the Brittany coast, S. latissima populations generally exhibited more patchy distribution when compared to the dense and continuous forests of the other two kelp species (Valero, personal observation). Genotyping of samples collected from additional localities should provide more information about S. latissima population structure along the coast of France, and in particular of Brittany.

Within Scandinavia, our data revealed moderate levels of connectivity between the $S$. latissima populations at the SWE and DEN sampling localities, and clear delimitation of the NOR 
population from those of the two former sampling sites. The observed admixture was less prevalent than between SB and NB (Figure 4). Overall, this intermediate degree of connectivity between the DEN and SWE populations suggests here also a role for currents in modulating S. latissima population structure in this section of the North Sea (the Skagerrak strait). There was almost no admixture between SWE/DEN and NOR (Figure 4c). This near absence of connectivity between the NOR and the DEN/SWE sampling localities is in accordance with expectations, given that these sites are separated by more than $2,000 \mathrm{~km}$. Overall, these analyses validated the applicability of the 25 microsatellite loci in elucidating S. latissima population structure.

Phylogeographic studies have demonstrated the effects of glacial-interglacial cycles during the Quaternary ( 2.6 Myr to present-times) on the patterns of contemporary genetic diversity, revealing several genetically rich refugia zones and a general trend of decrease in diversity with latitude (Hewitt 2004). In the northern Atlantic, several of these putative long-term climatic refugia have been identified for several marine species including seaweed. These refugia comprise Brittany/South Ireland (corresponding to the palaeo-Celtic Sea/Channel), northwestern Iberia, and for a smaller set of species, central-south Iberia and northwest Africa (Provan 2013; Neiva et al. 2016 for a recent review of North Atlantic Fucaceae). However, in the present study we did not detect a latitudinal gradient in genetic diversity as none of the localities displayed significantly higher genetic diversity than others (Figure 2) even if populations from Brittany, located in a putative refugia, were included in our data set. Erosion of genetic diversity may have occurred in this region due to low effective population size because Brittany was at the northern range limit of the species distribution during the colder periods of the Last Glacial Maximum. Reduced genetic diversity was observed for the kelp Saccorhiza polyschides in that region and was explained by models predicting marginal, although persistent, populations in the Brittany/Charentes regions (Assis et al. 2016). In addition, note that the S. latissima range extends as far south as Portugal (Bartsch et al. 2008), another predicted refugia of the northern Atlantic, and thus more genetically rich refugial populations might be found on the Iberian Peninsula. The three Scandinavian sampling localities all exhibited very low 
within-population gene diversity and allelic richness, similar to those of the French localities. This was

441 a somewhat surprising result as the lowest genetic diversity might have been expected for the NOR

442 population since it was sampled at the northern limit of the S. latissima distribution (Bartsch et al.

2008). This population is expected to show the same pattern of reduced diversity as has been reported for most North Atlantic Fucaceae (Neiva et al. 2016), which is the result of gene surfing at the leading edge of expansion during recolonization after the last glaciation period. populations of L. digitata and L. hyperborea (Billot et al. 2003; Couceiro et al. 2013; Robuchon et al. 2014). As discussed above, the relatively low within-population genetic diversity observed along the French coast is most probably explained by the small effective population size since populations are small and patchily distributed in this region. In contrast, the low $H_{s}$ estimates detected within the DEN and SWE sampling localities are counterintuitive as these sites are expected to form part of a large interconnected population(s) as they are located within the Skagerrak strait and the Norwegian side of the strait is known to harbour some of the largest kelp forests anywhere in Europe (Bekkby and Moy 2011). However, it has been observed that over the last five to 10 years extensive areas of the S. latissima forests have all but disappeared from along the coast of Norway (including in the Skagerrak strait), as well as from the coastlines of Germany, Denmark, and Sweden (Pehlke and Bartsch 2008; Andersen et al. 2011; Bekkby and Moy 2011; Andersen 2013). Thus it is conceivable that the fragmentation of populations, driven by anthropogenically induced kelp forest demise (Wahl et al. 2015), has occurred at such speed and to such an extent as to have resulted in a number of small, isolated patches that have retained only some fraction of their genetic diversity. However, we cannot exclude the hypothesis that the low within-population variability of the EST-derived 
microsatellites that was detected in our study is due to the fact that a proportion of the EST-SSR markers are located in coding regions and are thus generally less variable compared to randomly distributed genomic SSRs (see below).

The multilocus $F_{I S}$ was not significant within any of the six localities, ranging from -0.066 in SB to 0.095 in NB (Supplementary Table 3). Therefore, it is not possible to conclude that inbreeding was occurring within any of the sampled localities. Moreover, we did not detect any identical multilocus genotypes indicating that vegetative propagation (clonality) was not predominant within the studied localities.

Comparison of the S. latissima genetic diversity at the European scale revealed very high levels of differentiation and a total absence of admixture between the three French and the three Scandinavian localities (Table 3, Figure 4). The pairwise $F_{S T}$ estimates are particularly high, resembling the between rather than within-species estimates, and they are likely explained by the large geographic scale concerned in addition to the low dispersal capabilities of this seaweed species. However, there could also be other underlying factors, as discussed below.

Although SSRs are generally considered neutral genetic markers, EST-derived microsatellites are more likely to be involved in regulatory processes and to influence the differential expression of genes than microsatellites from other parts of the genome (Li et al. 2004). Thus the substantial genetic differentiation within S. latissima that was detected at the European level may not reflect only neutral genetic diversity, but also adaptive genetic diversity (Holderegger et al. 2006). In other words, if some of the newly developed loci are important for the regulation of genes vital for adaptation to different environmental regimes, then these loci would be under diversifying selection and hence become more differentiated between the disparate sampling localities than neutral SSR loci. Several studies have provided evidence of ecotypic differentiation between S. latissima populations from temperate (North Sea, Helgoland) or Arctic (Spitsbergen, Svalbard) regimes (Müller et al. 2008; Olischläger et al. 2014) with strong indications that differential expression of genes plays a major role in the adaption of the distinct S. latissima ecotypes to the local conditions (Heinrich et 

and from populations that have been exposed to different environmental conditions 2 ) the evidence for local adaptation within S. latissima populations, and 3) the potential role of EST-derived SSRs in regulating gene expression, it is conceivable that the high level of inter-population genetic differentiation detected in this study could be influenced by these factors rather than simply reflect the degree of inter-population connectivity. This scenario could also explain in part the low overall (i.e. over all loci) within-population heterozygosity, as it is conceivable that selection has acted to conserve the number of repeats for at least some of the loci within the localities. Indeed, a recent study that used 13 S. latissima-specific genomic SSRs to genotype 225 S. latissima sporophytes collected from one Swedish, one Norwegian, and six Danish sites, uncovered within-population gene diversity to range from 0.451 to 0.613 (Møller Nielsen et al. submitted), thus two to three times higher than what we have detected with the EST-SSRs. Therefore, the fact that the SSRs presented herein are EST-derived should be taken into account when interpreting our findings. A comparative study of both sets of markers on a larger sample size would allow outlier loci to be detected. In addition, the genomic location of our EST-derived SSRs could be investigated in order to find out which genes they are associated with and thus evaluate whether they potentially have a role in the adaptivity of the disparate S. latissima populations to the local conditions. positive correlation detected between the genetic and geographic distance measurements (Figure 3). This is a surprising result in light of a recent outcome of a meta-analysis, which found IBD for all of the macroalgae species analysed (Durrant et al. 2014). The macroalgae species included in the study by Durrant et al. (2014) originated from multiple taxonomic groups, exhibited various life histories, and inhabited varied environments. In the present study, the IBD signal may be obscured due to the DEN/SWE samples being more genetically differentiated from the Brittany localities than the levels of genetic differentiation between NOR and the Brittany localities (Table 3), even though the 
between the NOR locality and Brittany (Figure 1). Moreover, for all the Scandinavian versus French comparisons, the furthest locality (SB) was the least differentiated genetically whereas the closest locality (PDC) was the most diverse (Table 3). We have already noted that habitat discontinuity probably isolates the PDC population from other localities, resulting in increased pairwise $F_{S T}$ values that are greater than expected given the geographic distance. However, the reasons underlying the patterns involving the two Breton and three Scandinavian populations are open to speculation. Historical events could also have shaped the current population substructure, in particular vicariance due to the environmental and climatic changes that occurred during the last glacial maximum. As the spatial arrangement of the habitat patches will influence the IBD patterns (van Strien et al. 2015), another reason for the lack of detection of the IBD signal could be that the relative distances between the sampled populations are poorly replicated (for instance small distance between the two Brittany populations) and thus there is an uneven spread of the data points. Moreover, we cannot exclude the hypothesis that recent human impact may have modified S. latissima population structure, in particular in the Scandinavian region (see refs above), or that the effect of selection on EST-derived microsatellites prevents the detection of IBD signal (see above). Based on the results we present here, we are confident that this newly developed set of $S$. latissima-specific SSRs will prove to be a very useful genetic tool for this commercially important kelp species. These markers will find applicability in elucidating the population structure and dispersal patterns of this species, information that will be crucial for making informed and effective conservation and population management decisions (i.e. avoiding risk of transplantation by taking care to avoid the transfer of strains between different geographic regions). Moreover, this set of markers could be used to identify strains/genotypes of interest (for instance strains displaying commercially important traits), to measure the environmental impact of cultivation and harvesting of wild S. latissima populations on biodiversity (Klinger 2015), and to construct genetic linkage maps for this species. 
Acknowledgments This work benefited from the support of the French Government through the

545 National Research Agency with regards to an investment expenditure program IDEALG, which

546 reference is stated as ANR-10-BTBR-04, and was carried out within the context of the international

research network "Diversity, Evolution and Biotechnology of Marine Algae" (GDRI N 0803). The

authors are deeply indebted to the Service Mer \& Observation (SMO) of Roscoff, G. Cervin, and J.

Coyer for sampling. The authors would also like to thank Gildas Le Corguille of the ABiMS Platform,

Roscoff for his help with bioinformatics analyses. We are most grateful to the Biogenouest Genomics

their suggestions and comments.

\section{References}

Alberto F, Raimondi PT, Reed DC, Coelho NC, Leblois R, Whitmer A, Serrão EA (2010) Habitat continuity and geographic distance predict population genetic differentiation in giant kelp. Ecology 91 (1):49-56

Alberto F, Raimondi PT, Reed DC, Watson JR, Siegel DA, Mitarai S, Coelho N, Serrão EA (2011) Isolation by oceanographic distance explains genetic structure for Macrocystis pyrifera in the Santa Barbara Channel. Mol Ecol 20 (12):2543-2554

Andersen SG, Steen H, Christie H, Fredriksen S, Moy FE (2011) Seasonal patterns of sporophyte growth, fertility, fouling, and mortality of Saccharina latissima in Skagerrak, Norway: Implications for forest recovery. J Mar Biol 2011:1-8

Andersen SG (2013) Patterns of Saccharina latissima recruitment. PLOS One 8 (12):e81092

Assis J, Coelho NC, Lamy T, Valero M, Alberto F, Serrão EA (2016) Deep reefs are climatic refugia for genetic diversity of marine forests. J Biogeogr

Bartsch I, Wiencke C, Bischof K, Buchholz CM, Buck BH, Eggert A, Feuerpfeil P, Hanelt D, Jacobsen S, Karez R, Karsten U, Molis M, Roleda MY, Schubert H, Schumann R, Valentin K, Weinberger F, Wiese J (2008) The genus Laminaria sensu lato: recent insights and developments. European J Phycol 43 (1):1-86

Bekkby T, Moy FE (2011) Developing spatial models of sugar kelp (Saccharina latissima) potential distribution under natural conditions and areas of its disappearance in Skagerrak. Estuar Coast Shelf $S 95$ (4):477-483

Billot C, Engel CR, Rousvoal S, Kloareg B, Valero M (2003) Current patterns, habitat discontinuities and population genetic structure: the case of the kelp Laminaria digitata in the English Channel. Mar Ecol-Prog Ser 253 (111):21

Bolton JJ, Germann I, Luning K (1983) Hybridization between Atlantic and Pacific representatives of the Simplices section of Laminaria (Phaeophyta). Phycologia 22 (2):133-140

Bouck A, Vision T (2007) The molecular ecologist's guide to expressed sequence tags. Mol Ecol 16 (5):907-924

Brookfield J (1996) A simple new method for estimating null allele frequency from heterozygote deficiency. Mol Ecol 5 (3):453-455

Cie DK, Edwards MS (2011) Vertical distribution of kelp zoospores. Phycologia 50 (4):340-350 
Coleman MA, Roughan M, Macdonald HS, Connell SD, Gillanders BM, Kelaher BP, Steinberg PD (2011) Variation in the strength of continental boundary currents determines continent-wide connectivity in kelp. J Ecol 99 (4):1026-1032

Couceiro L, Robuchon M, Destombe C, Valero M (2013) Management and conservation of the kelp species Laminaria digitata: using genetic tools to explore the potential exporting role of the MPA “Parc naturel marin d'Iroise". Aquat Living Resour 26 (2):197-205

Cubry P, Pujade-Renaud V, Garcia D, Espeout S, Le Guen V, Granet F, Seguin M (2014) Development and characterization of a new set of 164 polymorphic EST-SSR markers for diversity and breeding studies in rubber tree (Hevea brasiliensis Müll. Arg.). Plant Breeding 133 (3):419426

Dong P, Wei YM, Chen GY, Li W, Wang JR, Nevo E, Zheng YL (2009) EST-SSR diversity correlated with ecological and genetic factors of wild emmer wheat in Israel. Hereditas 146 (1):1-10

Durrant HM, Burridge CP, Kelaher BP, Barrett NS, Edgar GJ, Coleman MA (2014) Implications of macroalgal isolation by distance for networks of marine protected areas. Conserv Biol 28 (2):438-445

Edwards K, Barker J, Daly A, Jones C, Karp A (1996) Microsatellite libraries enriched for several microsatellite sequences in plants. Biotechniques 20 (5):758

Ellis JR, Burke JM (2007) EST-SSRs as a resource for population genetic analyses. Heredity 99 (2):125132

Fraser Cl, Thiel M, Spencer HG, Waters JM (2010) Contemporary habitat discontinuity and historic glacial ice drive genetic divergence in Chilean kelp. BMC Evol Biol 10:203

Gerard VA, Du Bois K (1988) Temperature ecotypes near the southern boundary of the kelp Laminaria saccharina. Mar Biol 97 (4):575-580

Gerard VA (1988) Ecotypic differentiation in light-related traits of the kelp Laminaria saccharina. Mar Biol $97(1): 25-36$

Goudet J (2014) hierfstat: Estimation and tests of hierarchical F-statistics. R package version 0.04-14.

Guichoux E, Lagache L, Wagner S, Chaumeil P, Léger P, Lepais O, Lepoittevin C, Malausa T, Revardel E, Salin $F(2011)$ Current trends in microsatellite genotyping. Mol Ecol Resour 11 (4):591-611

Gupta P, Rustgi S, Sharma S, Singh R, Kumar N, Balyan H (2003) Transferable EST-SSR markers for the study of polymorphism and genetic diversity in bread wheat. Mol Genet Genomics 270 (4):315-323

Heinrich S, Valentin K, Frickenhaus S, John U, Wiencke C (2012) Transcriptomic analysis of acclimation to temperature and light stress in Saccharina latissima (Phaeophyceae). PLOS One 7 (8):e44342

Hewitt GM (2004) Genetic consequences of climatic oscillations in the Quaternary. Phil Trans R Soc Lond B 359 (1442):183-195

Holderegger R, Kamm U, Gugerli F (2006) Adaptive vs. neutral genetic diversity: implications for landscape genetics. Landscape Ecol 21 (6):797-807

Holleley CE, Geerts PG (2009) Multiplex Manager 1.0: a cross-platform computer program that plans and optimizes multiplex PCR. Biotechniques 46 (7):511-517

Hu J, Wang L, Li J (2011) Comparison of genomic SSR and EST-SSR markers for estimating genetic diversity in cucumber. Biol Plantarum 55 (3):577-580

Jombart T (2008) adegenet: a R package for the multivariate analysis of genetic markers. Bioinformatics 24 (11):1403-1405

Jombart T, Devillard S, Balloux F (2010) Discriminant analysis of principal components: a new method for the analysis of genetically structured populations. BMC Genet 11:94

Keenan K, McGinnity P, Cross TF, Crozier WW, Prodöhl PA (2013) diveRsity: an R package for the estimation and exploration of population genetics parameters and their associated errors. Method Ecol Evol 4 (8):782-788

Kim KS, Ratcliffe ST, French BW, Liu L, Sappington TW (2008) Utility of EST-derived SSRs as population genetics markers in a beetle. J Hered 99 (2):112-124 
Kinlan BP, Gaines SD (2003) Propagule dispersal in marine and terrestrial environments: a community perspective. Ecology 84 (8):2007-2020

Klinger T (2015) The role of seaweeds in the modern ocean. Pers Phycol:31-39

Kraemer P, Gerlach G (2013) Demerelate: Functions to calculate relatedness on diploid genetic data. $R$ package version 0.8-1

Li Y-C, Korol AB, Fahima T, Nevo E (2004) Microsatellites within genes: structure, function, and evolution. Mol Biol Evol 21 (6):991-1007

Liu F, Wang X, Yao J, Fu W, Duan D (2010) Development of expressed sequence tag-derived microsatellite markers for Saccharina (Laminaria) japonica. J Appl Phycol 22 (1):109-111

Liu F, Wang F, Duan D (2012) EST-SSR markers derived from Laminaria digitata and its transferable application in Saccharina japonica. J Appl Phycol 24 (3):501-505

Mauger S, Couceiro L, Valero M (2012) A simple and cost-effective method to synthesize an internal size standard amenable to use with a 5-dye system. Prime Research on Biotechnology 2:4046

Møller Nielsen M, Paulino C, Neiva J, Krause-Jensen D, Bruhn A, Serrão EA (Submitted) Genetic variability of Saccharina latissima along a salinity boundary in the North Sea-Baltic transition zone. J Phycol

Müller R, Wiencke C, Bischof K (2008) Interactive effects of UV radiation and temperature on microstages of Laminariales (Phaeophyceae) from the Arctic and North Sea. Clim Res 37 (23):203-213

Nei M (1987) Molecular evolutionary genetics. Columbia University Press, New York, New York

Neiva J, Serrão EA, Assis J, Pearson GA, Coyer JA, Olsen JL, Hoarau G, Valero M (2016) Climate oscillations, range shifts and phylogeographic patterns of North Atlantic Fucaceae. In: Hu Z-H, Fraser $\mathrm{Cl}$ (eds) Seaweed phylogeography. Springer

Oksanen J, Blanchet FG, Kindt R, Legendre P, Minchin PR, O'Hara RB, Simpson GL, Solymos P, Stevens $\mathrm{MHH}$, Wagner $\mathrm{H}$ (2015) vegan: Community Ecology Package. $\mathrm{R}$ package version 2.3-0

Olischläger M, Iniguez C, Gordillo FJ, Wiencke C (2014) Biochemical composition of temperate and Arctic populations of Saccharina latissima after exposure to increased $\mathrm{pCO}_{2}$ and temperature reveals ecotypic variation. Planta 240 (6):1213-1224

Paquette SR (2012) PopGenKit: Useful functions for (batch) file conversion and data resampling in microsatellite datasets. $R$ package version 1.0

Pehlke C, Bartsch I (2008) Changes in depth distribution and biomass of sublittoral seaweeds at Helgoland (North Sea) between 1970 and 2005. Clim Res 37 (2-3):135-147

Peteiro C, Freire Ó (2013) Biomass yield and morphological features of the seaweed Saccharina latissima cultivated at two different sites in a coastal bay in the Atlantic coast of Spain. J Appl Phycol 25 (1):205-213

Provan J (2013) The effects of past, present and future climate change on range-wide genetic diversity in northern North Atlantic marine species. Fron Biogeogr 5 (1):60-66

R Core Team (2015) R: A language and environment for statistical computing. R Foundation for Statistical Computing, Vienna, Austria

Rice WR (1989) Analyzing tables of statistical tests. Evolution:223-225

Robuchon M, Le Gall L, Mauger S, Valero M (2014) Contrasting genetic diversity patterns in two sister kelp species co-distributed along the coast of Brittany, France. Mol Ecol 23 (11):2669-2685

Rousset $F$ (1997) Genetic differentiation and estimation of gene flow from F-statistics under isolation by distance. Genetics 145 (4):1219-1228

Rousset F (2008) genepop'007: a complete re-implementation of the genepop software for Windows and Linux. Mol Ecol Resour 8 (1):103-106

Rozen S, Skaletsky H (1999) Primer3 on the WWW for General Users and for Biologist Programmers. In: Misener S, Krawetz S (eds) Bioinformatics Methods and Protocols, vol 132. Methods in Molecular Biology ${ }^{\mathrm{TM}}$. Humana Press, pp 365-386

Shi Y, Yang G, Liu Y, Liao M, Li X, Cong Y (2007) Development of 18 polymorphic microsatellite DNA markers of Laminaria japonica (Phaeophyceae). Mol Ecol Notes 7 (4):620-622 
van Strien MJ, Holderegger R, Van Heck HJ (2015) Isolation-by-distance in landscapes: considerations for landscape genetics. Heredity 114 (1):27-37

Teshome A, Bryngelsson T, Dagne K, Geleta M (2015) Assessment of genetic diversity in Ethiopian field pea (Pisum sativum L.) accessions with newly developed EST-SSR markers. BMC Genet $16(1): 102$

Thiel M, Gutow L (2005) The ecology of rafting in the marine environment. I. The floating substrata. Oceanography and Marine Biology: An Annual Review 42:181-264

Tseng C (2001) Algal biotechnology industries and research activities in China. J Appl Phycol 13 (4):375-380

Valero M, Destombe C, Mauger S, Ribout C, Engel CR, Daguin-Thiebaut C, Tellier F (2011) Using genetic tools for sustainable management of kelps: a literature review and the example of Laminaria digitata. CBM-Cahiers de Biologie Marine 52 (4):467

Van Oosterhout C, Hutchinson WF, Wills DP, Shipley P (2004) MICRO-CHECKER: software for identifying and correcting genotyping errors in microsatellite data. Mol Ecol Notes 4 (3):535538

Wahl M, Molis M, Hobday AJ, Dudgeon S, Neumann R, Steinberg P, Campbell AH, Marzinelli E, Connell S (2015) The responses of brown macroalgae to environmental change from local to global scales: direct versus ecologically mediated effects. Pers Phycol

Wang G, Tan X, Shen J, Li J, Zhang L, Sun J, Wang B, Weng M, Liu T (2011) Development of EST-SSR primers and their practicability test for Laminaria. Acta Oceanol Sin 30 (3):112-117

Weir BS, Cockerham CC (1984) Estimating F-statistics for the analysis of population structure. Evolution 38 (6):1358-1370

Woodhead M, Russell J, Squirrell J, Hollingsworth PM, Mackenzie K, Gibby M, Powell W (2005) Comparative analysis of population genetic structure in Athyrium distentifolium (Pteridophyta) using AFLPs and SSRs from anonymous and transcribed gene regions. Mol Ecol 14 (6):1681-1695

Ye N, Zhang X, Miao M, Fan X, Zheng Y, Xu D, Wang J, Zhou L, Wang D, Gao Y (2015) Saccharina genomes provide novel insight into kelp biology. Nature Communications 6

Zane L, Bargelloni L, Patarnello T (2002) Strategies for microsatellite isolation: a review. Mol Ecol 11 (1):1-16 
TABLE 1. Steps involved in the selection of 96 Saccharina latissima SSR loci from 7064 initial candidates obtained by analysis of cDNA library sequence data. The percentage of loci with specific motif types is also presented for each step of the selection process.

\begin{tabular}{lccccc}
\hline \hline Reduction step & $\mathrm{Di}$ & Tri & Tetra & Penta & Number of retained loci \\
\hline Sputnik output & $6 \%$ & $33 \%$ & $25 \%$ & $36 \%$ & 7064 \\
Primer3 output & $14 \%$ & $45 \%$ & $23 \%$ & $18 \%$ & 1878 \\
Loci with "N" base removed & $14 \%$ & $45 \%$ & $23 \%$ & $18 \%$ & 1871 \\
Repeat no. > 8 (di \& tri) \& $>5$ (tetra \& penta) & $20 \%$ & $30 \%$ & $32 \%$ & $19 \%$ & 184 \\
Final selection & $17 \%$ & $33 \%$ & $33 \%$ & $17 \%$ & 96 \\
\hline
\end{tabular}

Di refers to SSR loci with dinucleotide repeat motifs; Tri to SSR loci with trinucleotide repeat motifs; Tetra to SSR loci with tetranucleotide repeat motifs; Penta to SSR loci with pentanucleotide repeat motifs. 
TABLE 2. Technical information (primer sequence, dye, and multiplex), characteristics (repeat motif, expected product size, and observed size range), and polymorphism estimates ( $N_{A}, H_{O}, H_{T}, P I C$ ) for 32 EST-SSR loci based on amplification from genomic DNA of 96 Saccharina latissima sporophytes.

\begin{tabular}{|c|c|c|c|c|c|c|c|c|c|c|c|}
\hline Locus & Primer sequence (5'-3') & $\begin{array}{c}\text { Repeat } \\
\text { motif in the } \\
\text { EST }\end{array}$ & Dye & $\begin{array}{c}\text { Contig no. } \\
\text { on GenBank BioProject } \\
\text { PRJNA80101 }\end{array}$ & $\begin{array}{l}\text { Expected } \\
\text { product } \\
\text { size (bp) }\end{array}$ & $\begin{array}{l}\text { Observed } \\
\text { size } \\
\text { range (bp) }\end{array}$ & 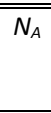 & $H_{0}$ & $H_{T}$ & $P I C$ & Multiplex \\
\hline Sacl-03 & $\begin{array}{c}\text { F: GTTGTTACGGTTGGCGTTG } \\
\text { R: TTCAATAATCGCAGGAAGCAC }\end{array}$ & $(\mathrm{CA})_{9}$ & PET & 10167 & 212 & $204-214$ & 6 & 0.479 & 0.679 & 0.625 & M1i \\
\hline Sacl-08 & $\begin{array}{l}\text { F: CAGACCTCACCAAGGCAAAG } \\
\text { R: TCCACGCACATACAGCAAA }\end{array}$ & $(\mathrm{TA})_{11}$ & PET & 14056 & 130 & $118-144$ & 4 & 0.073 & 0.071 & 0.069 & M3ii \\
\hline Sacl-09 & $\begin{array}{l}\text { F: ACCGTTCCCAATAACTACCC } \\
\text { R: ATGGACCTATCGCCCACA }\end{array}$ & $(\mathrm{AGC})_{13}$ & PET & 7028 & 332 & $320-332$ & 5 & 0.531 & 0.425 & 0.385 & M1i \\
\hline Sacl-11 & $\begin{array}{l}\text { F: AAGAGGTGGTTGCTCGGTT } \\
\text { R: CACTGATGGATGCCCTGTC }\end{array}$ & $(\mathrm{CTG})_{12}$ & FAM & 8341 & 302 & $294-306$ & 5 & 0.281 & 0.356 & 0.322 & M1i \\
\hline Sacl-13 & $\begin{array}{l}\text { F: CTCAGGTGTTCGGTGCCCT } \\
\text { R: GCTCGGTAGATGGTTAGTC }\end{array}$ & $(\mathrm{GCA})_{9}$ & FAM & 13741 & 268 & $235-244$ & 3 & 0.083 & 0.147 & 0.139 & M3i \\
\hline Sacl-19 & $\begin{array}{l}\text { F: GCGTATTCCTAAACACCTCCC } \\
\text { R: CGATGACTGCCACCACAG }\end{array}$ & $(\mathrm{ACC})_{9}$ & PET & 2896 & 175 & $163-184$ & 5 & 0.156 & 0.533 & 0.428 & $\mathrm{M} 2 \mathrm{i}$ \\
\hline Sacl-21 & $\begin{array}{l}\text { F: TCTCAACTCCAAACAGAGCGT } \\
\text { R: AGCAGCAGAAGCAGGCGA }\end{array}$ & $(\mathrm{GCT})_{9}$ & FAM & 17486 & 184 & $151-166$ & 5 & 0.177 & 0.203 & 0.194 & M3i \\
\hline Sacl-24 & $\begin{array}{l}\text { F: GCCAACCTATCATTCAAAGCA } \\
\text { R: TGTGGGAGCAACATCCTCA }\end{array}$ & $(\mathrm{TGA})_{11}$ & PET & 16267 & 103 & $87-132$ & 13 & 0.375 & 0.515 & 0.474 & $\mathrm{M} 2 \mathrm{i}$ \\
\hline Sacl-25 & $\begin{array}{c}\text { F: TTCGTTTCAGTTGGTGGGTT } \\
\text { R: TGCTGTAGTAGTGATTCTTCGCC }\end{array}$ & $(\mathrm{TTGA})_{23}$ & NED & 7352 & 339 & $323-343$ & 4 & 0.156 & 0.472 & 0.373 & M1i \\
\hline Sacl-27 & $\begin{array}{l}\text { F: GCGTTTGGTTAGCAGTGTGA } \\
\text { R: GTGCCCTCCCTACTCCCGT }\end{array}$ & $(\mathrm{AT})_{8}$ & NED & 17361 & 314 & $276-312$ & 5 & 0.000 & 0.082 & 0.081 & M3i \\
\hline Sacl-32 & $\begin{array}{c}\text { F: CTCGCTTGTCTGCTTGCTC } \\
\text { R: CTTTCGCCGTCACCTACTACA }\end{array}$ & $(\mathrm{GCTT})_{5}$ & PET & 2655 & 218 & $192-200$ & 3 & 0.031 & 0.031 & 0.031 & $\mathrm{M} 3 \mathrm{i}$ \\
\hline Sacl-33 & $\begin{array}{l}\text { F: TTTCCGCTCTGTCTCTCTCCT } \\
\text { R: AAATCACAACACAAGGCTGCT }\end{array}$ & $(\mathrm{CTTT})_{6}$ & FAM & 20594 & 204 & $182-186$ & 2 & 0.042 & 0.118 & 0.110 & M3ii \\
\hline Sacl-37 & $\begin{array}{l}\text { F: AACCGCTCTTTGTGTTTGATG } \\
\text { R: CTCCTTTCCCTCCCTCTCC }\end{array}$ & $(G G G A)_{6}$ & NED & 12415 & 149 & $146-154$ & 3 & 0.292 & 0.311 & 0.271 & $\mathrm{M} 1 \mathrm{i}$ \\
\hline Sacl-38 & $\begin{array}{c}\text { F: TACGATTGCGTGCGTTGT } \\
\text { R: ACGAAGAGATTGCGACCAAA }\end{array}$ & $(\mathrm{TA})_{7}$ & NED & 15061 & 136 & $122-152$ & 8 & 0.635 & 0.846 & 0.823 & $\mathrm{M} 2 \mathrm{i}$ \\
\hline Sacl-41 & $\begin{array}{l}\text { F: GTGGCGTTAGATGCTGTATGG } \\
\text { R: CGTGGACAAAGTAGGAAAGGG }\end{array}$ & $(\mathrm{GCTTA})_{11}$ & VIC & 136 & 340 & $262-352$ & 6 & 0.104 & 0.139 & 0.134 & M3ii \\
\hline Sacl-47 & $\begin{array}{l}\text { F: CGACACAATCGCAGTCAG } \\
\text { R: GCCCGACACACACTCAAGAC }\end{array}$ & $(\mathrm{CTTGA})_{6}$ & FAM & 11611 & 165 & $154-174$ & 3 & 0.365 & 0.411 & 0.353 & M1i \\
\hline Sacl-49 & $\begin{array}{l}\text { F: GCTCTCCACCTCGCACTAA } \\
\text { R: TACCGTCAGCCTCCCAGA }\end{array}$ & $(\mathrm{AT})_{13}$ & NED & 7113 & 333 & $315-335$ & 11 & 0.875 & 0.796 & 0.765 & M2ii \\
\hline Sacl-56 & F: GGAGAGCGTCGGATAGACC & $(\mathrm{AT})_{10}$ & VIC & 1453 & 132 & $112-118$ & 2 & 0.021 & 0.041 & 0.040 & M3i \\
\hline
\end{tabular}




\begin{tabular}{|c|c|c|c|c|c|c|c|c|c|c|c|}
\hline \multirow{3}{*}{ Sacl-60 } & R: GAGAATAGCACAGCAGCGAAC & \multirow{3}{*}{$(\mathrm{TGC})_{8}$} & \multirow{3}{*}{ VIC } & \multirow[b]{2}{*}{7664} & \multirow{3}{*}{200} & \multirow{3}{*}{$179-182$} & \multirow[b]{2}{*}{2} & \multirow{3}{*}{0.010} & \multirow{3}{*}{0.010} & \multirow{3}{*}{0.010} & \multirow[b]{2}{*}{ M3ii } \\
\hline & F: GTCCAGGTGCGTGCGTTAG & & & & & & & & & & \\
\hline & R: GCGAGCAGTTGAAAGGTGG & & & & & & & & & & \\
\hline \multirow[t]{2}{*}{ Sacl-65 } & F: ATCTCCCAAACCACACACAAG & $(\mathrm{CCA})_{10}$ & PET & 6095 & 344 & 339-369 & 6 & 0.115 & 0.643 & 0.580 & $\mathrm{M} 2 \mathrm{i}$ \\
\hline & R: CATCATCGTCAAGAACTCGG & & & & & & & & & & \\
\hline \multirow[t]{2}{*}{ Sacl-66 } & F: TATGTATGTCGGGAGACGGG & $(\mathrm{TTG})_{9}$ & PET & 20551 & 264 & $202-238$ & 12 & 0.521 & 0.835 & 0.813 & M2ii \\
\hline & R: GGGATTAGCAACTGAAACCA & & & & & & & & & & \\
\hline \multirow[t]{2}{*}{ Sacl-68 } & F: GGTGGGATTCTTTGGACGA & $(\mathrm{GGT})_{8}$ & FAM & 19139 & 162 & $155-158$ & 2 & 0.073 & 0.501 & 0.375 & $\mathrm{M} 2 \mathrm{i}$ \\
\hline & R: AAATGTGCTTGGGTCGGG & & & & & & & & & & \\
\hline \multirow[t]{2}{*}{ Sacl-74 } & F: CCTAAAGTTCTACCTGGGCAA & $(\mathrm{CCTT})_{6}$ & PET & 19201 & 279 & $256-284$ & 7 & 0.260 & 0.291 & 0.279 & $\mathrm{M} 1 \mathrm{i}$ \\
\hline & R: TCACAAGGACCACATTCCAAC & & & & & & & & & & \\
\hline \multirow[t]{2}{*}{ Sacl-75 } & F: CTCGTGTCGTCCCTTCATC & $(\mathrm{TC})_{5}$ & NED & 13067 & 256 & $236-238$ & 2 & 0.010 & 0.010 & 0.010 & M3ii \\
\hline & R: CTGTCTCCCAGAACTCGCC & & & & & & & & & & \\
\hline \multirow[t]{2}{*}{ Sacl-78 } & F: GTTGGTCGTGCTTCTAATCGG & $(\mathrm{GCTT})_{5}$ & FAM & 17312 & 291 & $265-289$ & 3 & 0.042 & 0.041 & 0.041 & M3i \\
\hline & R: GTCCATTTCTTGCTGTCGTG & & & & & & & & & & \\
\hline \multirow[t]{2}{*}{ Sacl-81 } & F: ACTTTGGCTCGGTCTGCTT & $(\mathrm{CG})_{6}$ & FAM & 9492 & 329 & $321-337$ & 6 & 0.469 & 0.694 & 0.642 & M2ii \\
\hline & R: CCTCCTCCCTTACCTACCTCC & & & & & & & & & & \\
\hline \multirow[t]{2}{*}{ Sacl-88 } & F: GAAACGGTGACTGACTGATGAC & $(\mathrm{AC})_{5}$ & PET & 1052 & 189 & 171-175 & 3 & 0.021 & 0.062 & 0.059 & M3ii \\
\hline & R: ACAAGGACGAACAGAGAACGA & & & & & & & & & & \\
\hline \multirow[t]{2}{*}{ Sacl-90 } & F: ATTGTGTTGCTGGATGAGGAC & $(\mathrm{GCAA})_{9}$ & PET & 4328 & 292 & 274-314 & 8 & 0.240 & 0.577 & 0.532 & M2ii \\
\hline & R: ACCTTCCGCTCTCTCGCT & & & & & & & & & & \\
\hline \multirow[t]{2}{*}{ Sacl-94 } & F: TGCCAAATAACACATTCCAGAG & $(\text { CGGTA })_{5}$ & VIC & 11651 & 256 & $243-298$ & 12 & 0.573 & 0.779 & 0.758 & M1ii \\
\hline & R: TGGTGCGAAGTCACGAAATAG & & & & & & & & & & \\
\hline \multirow[t]{2}{*}{ Sacl-95 } & F: GGGAAGGAGGAAGAAGGTG & $(\mathrm{GTTGC})_{6}$ & VIC & 19139 & 201 & 188-203 & 4 & 0.479 & 0.505 & 0.400 & $\mathrm{M} 2 \mathrm{i}$ \\
\hline & R: TAGCGGGAAAGAACGGGTAGT & & & & & & & & & & \\
\hline
\end{tabular}

Primer sequences exclude the M13(-21) universal sequence tag; F, forward primer (labelled with florescent dye); R, reverse primer; Expected product size, size in base pairs (bp) of the expressed sequence tag (EST) that possessed the microsatellite locus; $N_{A}$, number of alleles; $H_{O}$, observed heterozygosity; $H_{T}$, overall gene diversity; PIC, polymorphic information content. $100 \%$ amplification was achieved for all loci. 
TABLE 3. Pairwise $F_{S T}$ estimates for the six sampling localities.

\begin{tabular}{lllllll}
\hline \hline & SB & NB & PDC & DEN & SWE & NOR \\
\hline SB & 0.000 & & & & & \\
NB & 0.077 & 0.000 & & & & \\
PDC & 0.179 & 0.157 & 0.000 & & & \\
DEN & 0.481 & 0.517 & 0.562 & 0.000 & & \\
SWE & 0.472 & 0.509 & 0.559 & 0.120 & 0.000 & 0.000 \\
NOR & 0.358 & 0.390 & 0.431 & 0.291 & 0.268 &
\end{tabular}

All comparisons are significant 
SUPPLEMENTARY TABLE 1. Technical information (primer sequence, and dye), characteristics (repeat motif, expected product size, and observed size range), and polymorphism estimates ( $\left.N_{A}, H_{O}, H_{T}, P I C\right)$ for two EST-SSR loci based on amplification from genomic DNA of 76 Saccharina latissima sporophytes for Sacl-70 and 72 s. latissima sporophytes for Sacl-77.

\begin{tabular}{|c|c|c|c|c|c|c|c|c|c|c|}
\hline Locus & Primer sequence $\left(5^{\prime}-3^{\prime}\right)$ & $\begin{array}{c}\text { Repeat } \\
\text { motif in the } \\
\text { EST }\end{array}$ & Dye & $\begin{array}{c}\text { Contig no. } \\
\text { on GenBank BioProject } \\
\text { PRJNA80101 }\end{array}$ & $\begin{array}{l}\text { Expected } \\
\text { product } \\
\text { size }(b p)\end{array}$ & $\begin{array}{l}\text { Observed } \\
\text { size } \\
\text { range }(b p)\end{array}$ & $N_{A}$ & $H_{0}$ & $H_{T}$ & $P I C$ \\
\hline \multirow[t]{2}{*}{ Sacl-70 } & F: GTTAGGGCAAGGTGTGTGGT & $(\mathrm{TAC})_{8}$ & M13-VIC & 1667 & 258 & $258-264$ & 2 & 0.211 & 0.317 & 0.267 \\
\hline & R: AGAACCCAGAAGAAGCAGCAA & & & & & & & & & \\
\hline Sacl-77 & F: GTCACTCAGGCAGCGGTT & $(\mathrm{CT})_{6}$ & M13-VIC & 18198 & 340 & $236-338$ & 7 & 0.375 & 0.730 & 0.686 \\
\hline
\end{tabular}

Primer sequences exclude the M13(-21) universal sequence tag; F, forward primer (labelled with florescent dye); R, reverse primer; Expected product size, size in base pairs (bp) of the expressed sequence tag (EST) that possessed the microsatellite locus; $N_{A}$, number of alleles; $H_{O}$, observed heterozygosity; $H_{T}$, overall gene diversity; PIC, polymorphic information content. 
SUPPLEMENTARY TABLE 2. Technical information (primer sequence, and dye), and characteristics (repeat motif, expected product size, and observed product size) for 15 EST-SSR loci that were monomorphic within a sample of 96 S. latissima sporophytes.

\begin{tabular}{|c|c|c|c|c|c|c|}
\hline Locus & Primer sequence (5'-3') & $\begin{array}{c}\text { Repeat } \\
\text { motif in the } \\
\text { EST }\end{array}$ & Dye & $\begin{array}{c}\text { Contig no. } \\
\text { on GenBank BioProject } \\
\text { PRJNA80101 }\end{array}$ & $\begin{array}{l}\text { Expected } \\
\text { product } \\
\text { size }(b p)\end{array}$ & $\begin{array}{l}\text { Observed } \\
\text { product } \\
\text { size (bp) }\end{array}$ \\
\hline Sacl-16 & $\begin{array}{c}\text { F: GGAGGAGGAGGAGGTTTAGGT } \\
\text { R: CTTATGTCGCCTTGGATGGA }\end{array}$ & $(\mathrm{CAA})_{10}$ & M13-PET & 10750 & 223 & 223 \\
\hline Sacl-20 & $\begin{array}{l}\text { F: CGGAAACGGGAGTCTATCTG } \\
\text { R: GCTGCTGGAGTTGCTGTTG }\end{array}$ & $(\mathrm{CAG})_{10}$ & M13-PET & 2190 & 187 & 186 \\
\hline Sacl-22 & $\begin{array}{l}\text { F: CTCACAGCCAACATCACACAC } \\
\text { R: AACGAGAAGAGCAAGAGCCAC }\end{array}$ & $(\mathrm{CAC})_{9}$ & M13-VIC & 1442 & 183 & 180 \\
\hline Sacl-29 & $\begin{array}{l}\text { F: GCACTTTCTTCGTCTCGTGTG } \\
\text { R: ACCACCACCACCACTTTGTT }\end{array}$ & $(\mathrm{TTTA})_{5}$ & M13-NED & 11922 & 264 & 264 \\
\hline Sacl-44 & $\begin{array}{l}\text { F: AGCAAAGAACCGAACAAAGAA } \\
\text { R: AGACCGAAGAAGAAATGACGG }\end{array}$ & $(\mathrm{ACCGA})_{6}$ & M13-PET & 9226 & 230 & 230 \\
\hline Sacl-45 & $\begin{array}{l}\text { F: AGTAGCGGCAGGGAGGAAC } \\
\text { R: GACGCAGAGAGACACAGAACC }\end{array}$ & $(\mathrm{TGGTC})_{7}$ & M13-FAM & 17892 & 203 & 203 \\
\hline Sacl-46 & $\begin{array}{c}\text { F: TTTCGGTATCATCGTGTTC } \\
\text { R: TCCATCCATCCATCAATCTAA }\end{array}$ & $(\text { GGGTT })_{8}$ & M13-VIC & 1566 & 187 & 187 \\
\hline Sacl-48 & $\begin{array}{l}\text { F: AAAGGGACTGGATTTGTCT } \\
\text { R: CCTACTTCTCGGCTTGTTGA }\end{array}$ & $(\text { TATGC })_{5}$ & M13-PET & 3016 & 136 & 136 \\
\hline Sacl-50 & $\begin{array}{l}\text { F: AGCACCCGTAGGTAGAAGGAA } \\
\text { R: GTGGGAGGAGGAAACCATAAC }\end{array}$ & $(\mathrm{CT})_{8}$ & M13-VIC & 292 & 247 & 243 \\
\hline Sacl-59 & $\begin{array}{l}\text { F: GGAGGTGTGTGGTGGACTTG } \\
\text { R: ACAATGGCAGATGAGGAACT }\end{array}$ & $(T G A)_{8}$ & M13-NED & 8272 & 250 & 247 \\
\hline Sacl-63 & $\begin{array}{l}\text { F: TTGTTGTTGGTGTTGCTGTGT } \\
\text { R: CTGGGATAGATGGAGATGGG }\end{array}$ & $(\mathrm{AGC})_{8}$ & M13-NED & 15110 & 230 & 229 \\
\hline Sacl-71 & $\begin{array}{c}\text { F: CGAAGGAAGTGAGAGTGACGA } \\
\text { R: TTCTGAGGAGCAACGACAAG }\end{array}$ & $(G A G)_{8}$ & M13-NED & 11027 & 215 & 215 \\
\hline Sacl-80 & $\begin{array}{c}\text { F: AGCCTGCGTCTCAACACC } \\
\text { R: CCGTGCTACAGTTTCCTATCC }\end{array}$ & $(\mathrm{GCAT})_{6}$ & M13-PET & 3817 & 203 & 203 \\
\hline Sacl-86 & $\begin{array}{l}\text { F: ATGTTGCCGTTGTTTAGGTCA } \\
\text { R: TTGATTGGTCTGGTTTGGTTT }\end{array}$ & $(\text { CATC })_{6}$ & M13-VIC & 2253 & 258 & 254 \\
\hline Sacl-91 & $\begin{array}{l}\text { F: TGCTTGGATTTATTAGAGTTT } \\
\text { R: TCTGCCTTGCCTTGCTTG }\end{array}$ & $(\mathrm{AGGCC})_{5}$ & M13-NED & 19844 & 248 & 243 \\
\hline
\end{tabular}

Primer sequences exclude the M13(-21) universal sequence tag; F, forward primer (labelled with florescent dye); R, reverse primer; Expected product size, size in base pairs (bp) of the expressed sequence tag (EST) that possessed the microsatellite locus. $100 \%$ amplification was achieved for all loci. 
SUPPLEMENTARY TABLE 3. Characteristics of 32 polymorphic S. latissima microsatellite loci in three French populations: SB (Mousterlin), NB (Roscoff), and PDC (Audresselles).

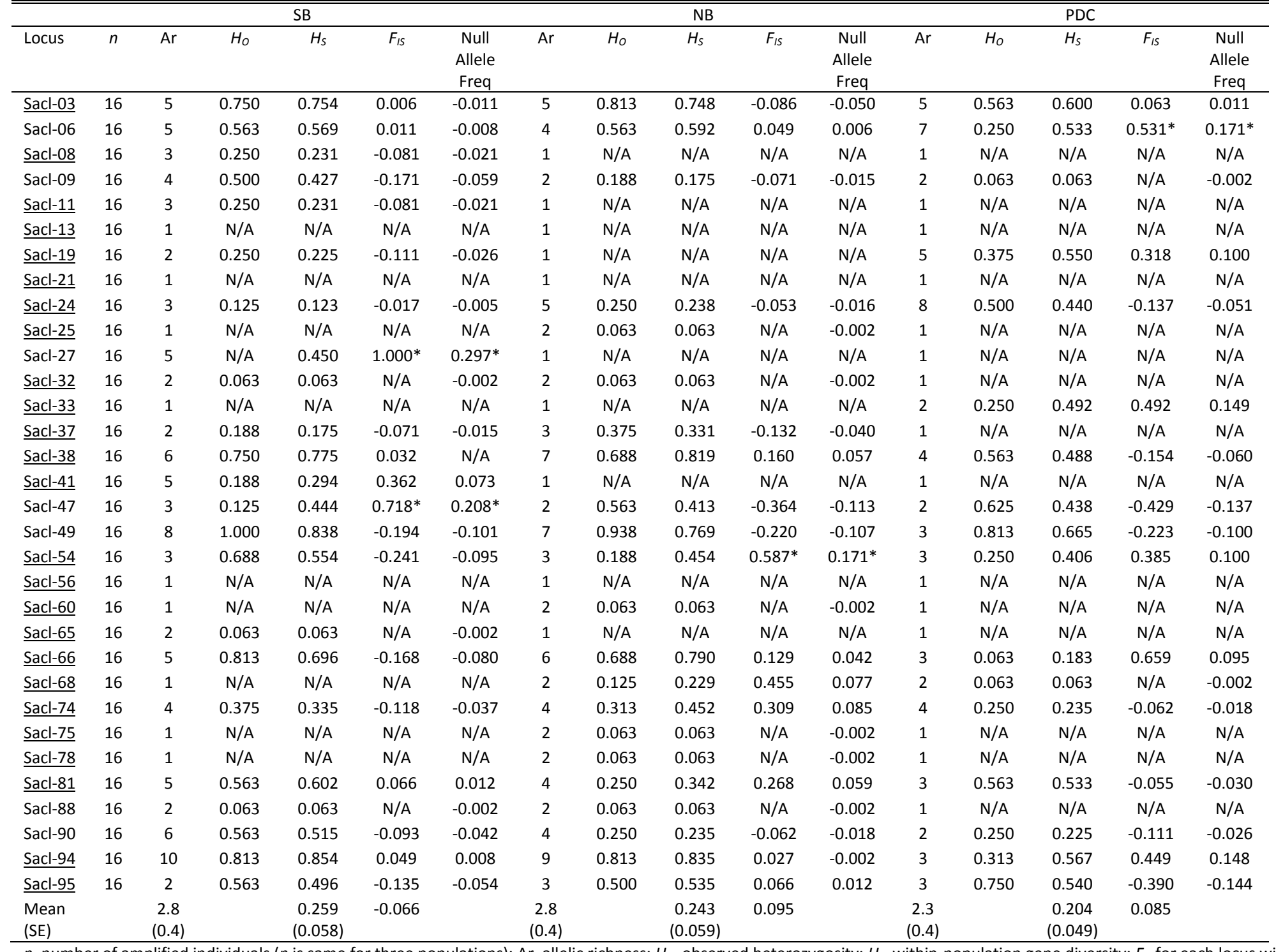

$n$, number of amplified individuals ( $n$ is same for three populations); Ar, allelic richness; $H_{0}$, observed heterozygosity; $H_{s}$, within-population gene diversity; $F_{I s}$ for each locus within each locality estimated using the Nei \& Chesser 1983 equation; Null allele frequency estimated using Brookfield I equation (Brookfield 1986); SE, standard error. * indicates significant $F_{I S}$ (p-value below 0.01), or loci showing evidence for null alleles.

Underlined loci are the 25 retained for the population genetics analyses. Within population Ar and $H_{s}$ averages (bottom row) calculated for the 25 underlined loci only. $F_{I S}$ for each population is the multilocus

estimate of Wright's inbreeding coefficient (calculated for the 25 underlined loci only). 
SUPPLEMENTARY TABLE 3 continued. Characteristics of 32 polymorphic S. latissima microsatellite loci in three Scandinavian populations: DEN (Ebeltoft, Denmark), SWE (Tjarno, Sweden), and NOR (Ny-Alesund, Norway), and in all six populations (French and Scandinavian) combined (ALL POPS).

\begin{tabular}{|c|c|c|c|c|c|c|c|c|c|c|c|c|c|c|c|c|c|c|c|c|}
\hline & & & & DEN & & & & & SWE & & & & & NOR & & & & ALL & DPS & \\
\hline Locus & $n$ & $\mathrm{Ar}$ & $H_{0}$ & $H_{s}$ & $F_{I S}$ & $\begin{array}{c}\text { Null } \\
\text { Allele } \\
\text { Freq }\end{array}$ & $\mathrm{Ar}$ & $H_{0}$ & $H_{S}$ & $F_{I S}$ & $\begin{array}{c}\text { Null } \\
\text { Allele } \\
\text { Freq }\end{array}$ & $\mathrm{Ar}$ & $H_{0}$ & $H_{s}$ & $F_{I S}$ & $\begin{array}{c}\text { Null } \\
\text { Allele } \\
\text { Freq }\end{array}$ & $\begin{array}{l}\text { Ar } \\
\text { (SE) }\end{array}$ & $\begin{array}{c}H_{S} \\
(\mathrm{SE})\end{array}$ & $F_{i s}$ & $F_{S T}$ \\
\hline$\underline{\text { Sacl-03 }}$ & 16 & 3 & 0.250 & 0.231 & -0.081 & -0.021 & 3 & 0.125 & 0.123 & -0.017 & -0.005 & 2 & 0.375 & 0.388 & 0.032 & N/A & $\begin{array}{c}3.833 \\
(0.543)\end{array}$ & $\begin{array}{c}0.474 \\
(0.109)\end{array}$ & -0.011 & 0.302 \\
\hline Sacl-06 & 16 & 3 & 0.125 & 0.338 & 0.630 & $0.148^{*}$ & 6 & 0.125 & 0.531 & $0.765^{*}$ & $0.251^{*}$ & 1 & N/A & N/A & N/A & N/A & $\begin{array}{c}4.333 \\
(0.882)\end{array}$ & $\begin{array}{c}0.427 \\
(0.093)\end{array}$ & 0.366 & 0.244 \\
\hline Sacl-08 & 16 & 2 & 0.063 & 0.063 & N/A & -0.002 & 1 & N/A & N/A & N/A & $\mathrm{N} / \mathrm{A}$ & 2 & 0.125 & 0.121 & -0.035 & -0.007 & $\begin{array}{c}1.667 \\
(0.333)\end{array}$ & $\begin{array}{c}0.069 \\
(0.038)\end{array}$ & -0.055 & 0.032 \\
\hline Sacl-09 & 16 & 2 & 0.938 & 0.500 & $-0.875^{*}$ & -0.293 & 2 & 0.813 & 0.488 & $-0.667^{*}$ & -0.223 & 3 & 0.688 & 0.517 & -0.331 & -0.121 & $\begin{array}{c}2.500 \\
(0.342)\end{array}$ & $\begin{array}{c}0.361 \\
(0.079)\end{array}$ & -0.470 & 0.149 \\
\hline$\underline{\text { Sacl-11 }}$ & 16 & 3 & 0.688 & 0.596 & -0.154 & -0.068 & 2 & 0.500 & 0.517 & 0.032 & N/A & 4 & 0.250 & 0.235 & -0.062 & -0.018 & $\begin{array}{c}2.333 \\
(0.494)\end{array}$ & $\begin{array}{c}0.263 \\
(0.103)\end{array}$ & -0.069 & 0.260 \\
\hline$\underline{\text { Sacl-13 }}$ & 16 & 1 & N/A & N/A & N/A & N/A & 1 & N/A & N/A & N/A & N/A & 3 & 0.500 & 0.590 & 0.152 & 0.044 & $\begin{array}{c}1.333 \\
(0.333)\end{array}$ & $\begin{array}{c}0.098 \\
(0.098)\end{array}$ & 0.152 & 0.330 \\
\hline$\underline{\text { Sacl-19 }}$ & 16 & 2 & 0.063 & 0.063 & $\mathrm{~N} / \mathrm{A}$ & -0.002 & 1 & N/A & N/A & $\mathrm{N} / \mathrm{A}$ & N/A & 2 & 0.250 & 0.225 & -0.111 & -0.026 & $\begin{array}{c}2.167 \\
(0.601)\end{array}$ & $\begin{array}{c}0.177 \\
(0.086)\end{array}$ & 0.118 & 0.668 \\
\hline$\underline{\text { Sacl-21 }}$ & 16 & 3 & 0.188 & 0.179 & -0.047 & -0.012 & 2 & 0.438 & 0.350 & -0.250 & -0.071 & 4 & 0.438 & 0.533 & 0.180 & 0.050 & $\begin{array}{c}2.000 \\
(0.516)\end{array}$ & $\begin{array}{c}0.177 \\
(0.091)\end{array}$ & N/A & 0.128 \\
\hline Sacl-24 & 16 & 2 & 0.500 & 0.442 & -0.132 & -0.049 & 4 & 0.625 & 0.573 & -0.091 & -0.044 & 4 & 0.250 & 0.552 & $0.547^{*}$ & $0.181^{*}$ & $\begin{array}{c}4.333 \\
(0.843)\end{array}$ & $\begin{array}{c}0.394 \\
(0.073)\end{array}$ & 0.049 & 0.234 \\
\hline$\underline{\text { Sacl-25 }}$ & 16 & 3 & 0.188 & 0.179 & -0.047 & -0.012 & 2 & 0.375 & 0.313 & -0.200 & -0.054 & 2 & 0.313 & 0.471 & 0.336 & 0.096 & $\begin{array}{c}1.833 \\
(0.307)\end{array}$ & $\begin{array}{c}0.171 \\
(0.078)\end{array}$ & 0.085 & 0.638 \\
\hline Sacl-27 & 16 & 1 & N/A & $\mathrm{N} / \mathrm{A}$ & N/A & $\mathrm{N} / \mathrm{A}$ & 1 & N/A & N/A & $\mathrm{N} / \mathrm{A}$ & N/A & 1 & N/A & $\mathrm{N} / \mathrm{A}$ & N/A & $\mathrm{N} / \mathrm{A}$ & $\begin{array}{c}1.667 \\
(0.667)\end{array}$ & $\begin{array}{c}0.075 \\
(0.075)\end{array}$ & 1.000 & 0.085 \\
\hline$\underline{\text { Sacl-32 }}$ & 16 & 2 & 0.063 & 0.063 & N/A & -0.002 & 1 & N/A & N/A & N/A & N/A & 1 & N/A & N/A & N/A & N/A & $\begin{array}{c}1.500 \\
(0.224)\end{array}$ & $\begin{array}{c}0.031 \\
(0.014)\end{array}$ & N/A & -0.007 \\
\hline$\underline{\text { Sacl-33 }}$ & 16 & 1 & N/A & N/A & N/A & N/A & 1 & N/A & N/A & N/A & N/A & 1 & N/A & $\mathrm{N} / \mathrm{A}$ & N/A & N/A & $\begin{array}{c}1.167 \\
(0.167)\end{array}$ & $\begin{array}{c}0.082 \\
(0.082)\end{array}$ & 0.492 & 0.305 \\
\hline Sacl-37 & 16 & 2 & 0.438 & 0.350 & -0.250 & -0.071 & 2 & 0.563 & 0.513 & -0.098 & -0.043 & 2 & 0.188 & 0.175 & -0.071 & -0.015 & $\begin{array}{c}2.000 \\
(0.258)\end{array}$ & $\begin{array}{c}0.257 \\
(0.073)\end{array}$ & -0.134 & 0.173 \\
\hline$\underline{\text { Sacl-38 }}$ & 16 & 3 & 0.500 & 0.540 & 0.073 & 0.014 & 2 & 0.375 & 0.446 & 0.159 & 0.038 & 5 & 0.938 & 0.742 & -0.264 & -0.123 & $\begin{array}{c}4.500 \\
(0.764)\end{array}$ & $\begin{array}{c}0.635 \\
(0.066)\end{array}$ & -0.001 & 0.249 \\
\hline Sacl-41 & 16 & 1 & N/A & N/A & N/A & N/A & 1 & N/A & N/A & N/A & N/A & 2 & 0.438 & 0.417 & -0.050 & -0.024 & $\begin{array}{c}1.833 \\
(0.654)\end{array}$ & $\begin{array}{c}0.118 \\
(0.077)\end{array}$ & 0.120 & 0.147 \\
\hline Sacl-47 & 16 & 3 & 0.188 & 0.179 & -0.047 & -0.012 & 3 & 0.500 & 0.640 & 0.218 & 0.071 & 2 & 0.188 & 0.175 & -0.071 & -0.015 & $\begin{array}{c}2.500 \\
(0.224)\end{array}$ & $\begin{array}{c}0.381 \\
(0.073)\end{array}$ & 0.044 & 0.072 \\
\hline Sacl-49 & 16 & 4 & 1.000 & 0.585 & $-0.708^{*}$ & -0.266 & 3 & 0.875 & 0.523 & $-0.673^{*}$ & -0.236 & 4 & 0.625 & 0.627 & 0.003 & -0.011 & $\begin{array}{c}4.833 \\
(0.872)\end{array}$ & $\begin{array}{c}0.668 \\
(0.048)\end{array}$ & -0.311 & 0.161 \\
\hline$\underline{\text { Sacl-54 }}$ & 16 & 2 & 0.250 & 0.225 & -0.111 & -0.026 & 1 & N/A & N/A & $\mathrm{N} / \mathrm{A}$ & $\mathrm{N} / \mathrm{A}$ & 3 & 0.563 & 0.450 & -0.250 & -0.086 & $\begin{array}{c}2.500 \\
(0.342)\end{array}$ & $\begin{array}{c}0.348 \\
(0.082)\end{array}$ & 0.073 & 0.443 \\
\hline$\underline{\text { Sacl-56 }}$ & 16 & 2 & 0.125 & 0.229 & 0.455 & 0.077 & 1 & N/A & N/A & N/A & $\mathrm{N} / \mathrm{A}$ & 1 & N/A & N/A & N/A & N/A & $\begin{array}{c}1.167 \\
(0.167)\end{array}$ & $\begin{array}{c}0.038 \\
(0.038)\end{array}$ & 0.455 & 0.070 \\
\hline$\underline{\text { Sacl-60 }}$ & 16 & 1 & N/A & N/A & $\mathrm{N} / \mathrm{A}$ & $\mathrm{N} / \mathrm{A}$ & 1 & N/A & $\mathrm{N} / \mathrm{A}$ & N/A & $\mathrm{N} / \mathrm{A}$ & 1 & $\mathrm{~N} / \mathrm{A}$ & N/A & N/A & $\mathrm{N} / \mathrm{A}$ & $\begin{array}{c}1.167 \\
(0.167)\end{array}$ & $\begin{array}{c}0.010 \\
(0.010)\end{array}$ & N/A & N/A \\
\hline$\underline{\text { Sacl-65 }}$ & 16 & 1 & N/A & N/A & N/A & N/A & 3 & 0.375 & 0.402 & 0.067 & 0.010 & 3 & 0.250 & 0.558 & $0.552^{*}$ & $0.184^{*}$ & $\begin{array}{c}1.833 \\
(0.401)\end{array}$ & $\begin{array}{c}0.170 \\
(0.100)\end{array}$ & 0.328 & 0.735 \\
\hline$\underline{\text { Sacl-66 }}$ & 16 & 5 & 0.625 & 0.640 & 0.023 & -0.004 & 3 & 0.375 & 0.323 & -0.161 & -0.046 & 3 & 0.563 & 0.600 & 0.063 & 0.011 & 4.167 & 0.539 & 0.033 & 0.355 \\
\hline
\end{tabular}




\begin{tabular}{|c|c|c|c|c|c|c|c|c|c|c|c|c|c|c|c|c|c|c|c|c|}
\hline & & & & & & & & & & & & & & & & & $(0.543)$ & $(0.096)$ & & \\
\hline Sacl-68 & 16 & 1 & N/A & $\mathrm{N} / \mathrm{A}$ & N/A & $\mathrm{N} / \mathrm{A}$ & 1 & $\mathrm{~N} / \mathrm{A}$ & N/A & N/A & N/A & 2 & 0.250 & 0.225 & -0.111 & -0.026 & $\begin{array}{c}1.500 \\
(0.224)\end{array}$ & $\begin{array}{c}0.086 \\
(0.046)\end{array}$ & 0.153 & 0.828 \\
\hline$\underline{\text { Sacl-74 }}$ & 16 & 1 & N/A & $\mathrm{N} / \mathrm{A}$ & $\mathrm{N} / \mathrm{A}$ & $\mathrm{N} / \mathrm{A}$ & 2 & 0.125 & 0.121 & -0.035 & -0.007 & 2 & 0.500 & 0.442 & -0.132 & -0.049 & $\begin{array}{c}2.833 \\
(0.543)\end{array}$ & $\begin{array}{c}0.264 \\
(0.074)\end{array}$ & 0.015 & 0.093 \\
\hline$\underline{\text { Sacl-75 }}$ & 16 & 1 & N/A & N/A & $\mathrm{N} / \mathrm{A}$ & $\mathrm{N} / \mathrm{A}$ & 1 & N/A & N/A & N/A & $\mathrm{N} / \mathrm{A}$ & 1 & $\mathrm{~N} / \mathrm{A}$ & N/A & $\mathrm{N} / \mathrm{A}$ & $\mathrm{N} / \mathrm{A}$ & $\begin{array}{c}1.167 \\
(0.167)\end{array}$ & $\begin{array}{c}0.010 \\
(0.010)\end{array}$ & $\mathrm{N} / \mathrm{A}$ & $\mathrm{N} / \mathrm{A}$ \\
\hline$\underline{\text { Sacl-78 }}$ & 16 & 1 & $\mathrm{~N} / \mathrm{A}$ & $\mathrm{N} / \mathrm{A}$ & $\mathrm{N} / \mathrm{A}$ & N/A & 1 & N/A & N/A & $\mathrm{N} / \mathrm{A}$ & N/A & 2 & 0.188 & 0.175 & -0.071 & -0.015 & $\begin{array}{c}1.333 \\
(0.211)\end{array}$ & $\begin{array}{c}0.040 \\
(0.029)\end{array}$ & -0.053 & 0.038 \\
\hline$\underline{\text { Sacl-81 }}$ & 16 & 3 & 0.500 & 0.460 & -0.086 & -0.036 & 4 & 0.563 & 0.567 & 0.007 & -0.009 & 2 & 0.375 & 0.313 & -0.200 & -0.054 & $\begin{array}{c}3.500 \\
(0.428)\end{array}$ & $\begin{array}{c}0.469 \\
(0.049)\end{array}$ & 0.002 & 0.324 \\
\hline Sacl-88 & 16 & 2 & N/A & 0.233 & 1.000 & $0.180^{*}$ & 1 & N/A & N/A & N/A & N/A & 1 & N/A & N/A & N/A & N/A & $\begin{array}{c}1.500 \\
(0.224)\end{array}$ & $\begin{array}{c}0.060 \\
(0.037)\end{array}$ & 0.651 & 0.029 \\
\hline Sacl-90 & 16 & 3 & 0.063 & 0.596 & 0.895* & $0.319 *$ & 5 & 0.188 & 0.629 & $0.702^{*}$ & $0.256^{*}$ & 3 & 0.125 & 0.181 & 0.310 & 0.042 & $\begin{array}{c}3.833 \\
(0.601)\end{array}$ & $\begin{array}{c}0.397 \\
(0.084)\end{array}$ & 0.396 & 0.312 \\
\hline$\underline{\text { Sacl-94 }}$ & 16 & 8 & 0.688 & 0.725 & 0.052 & 0.008 & 8 & 0.313 & 0.748 & $0.582^{*}$ & $0.233^{*}$ & 6 & 0.500 & 0.629 & 0.205 & 0.066 & $\begin{array}{c}7.333 \\
(1.022)\end{array}$ & $\begin{array}{c}0.726 \\
(0.046)\end{array}$ & 0.211 & 0.068 \\
\hline$\underline{\text { Sacl-95 }}$ & 16 & 3 & 0.438 & 0.488 & 0.103 & 0.023 & 3 & 0.563 & 0.521 & -0.080 & -0.038 & 3 & 0.063 & 0.238 & 0.737 & $0.132^{*}$ & $\begin{array}{c}2.833 \\
(0.167)\end{array}$ & $\begin{array}{c}0.469 \\
(0.047)\end{array}$ & -0.021 & 0.070 \\
\hline $\begin{array}{l}\text { Mean } \\
\text { (SE) }\end{array}$ & & $\begin{array}{c}2.3 \\
(0.3) \\
\end{array}$ & & $\begin{array}{c}0.219 \\
(0.048)\end{array}$ & -0.049 & & $\begin{array}{c}2.1 \\
(0.3) \\
\end{array}$ & & $\begin{array}{c}0.221 \\
(0.050) \\
\end{array}$ & 0.004 & & $\begin{array}{c}2.5 \\
(0.3) \\
\end{array}$ & & $\begin{array}{c}0.323 \\
(0.046) \\
\end{array}$ & 0.063 & & & $\begin{array}{c}0.245 \\
(0.042)\end{array}$ & $\begin{array}{c}0.078 \\
(0.031)\end{array}$ & $\begin{array}{c}0.259 \\
(0.048)\end{array}$ \\
\hline
\end{tabular}

$n$, number of amplified individuals ( $n$ is same for three populations); Ar, allelic richness; $H_{0}$, observed heterozygosity; $H_{s}$, within-population gene diversity; $F_{I S}$ for each locus within each locality estimated using the Nei

\& Chesser 1983 equation; Null allele frequency estimated using Brookfield I equation (Brookfield 1986); SE, standard error. ${ }^{*}$ indicates significant $F_{I S}(p$-value below 0.01 ), or loci showing evidence for null alleles. For each locus the ALL POPS Ar and $H_{S}$ are the means of these two parameters over the six sampling localities (SB, NB, PDC, DEN, SWE, NOR), $F_{I S}$ was calculated using equation $F_{I S}=1-H_{O} / H_{S}$, and $F_{S T}$ was calculated using equation $F_{S T}=1-H_{O} / H_{T}$, where $H_{O}$ and $H_{S}$ are averages of these values across the six populations, and $H_{T}$ is the overall gene diversity (shown in Table 1 ). Underlined loci are the 25 retained for the population genetics analyses. Within population $\mathrm{Ar}$ and $H_{s}$ averages and the ALL POPS $H_{S}, F_{I S}$, and $F_{S T}$ averages (bottom row) calculated for the 25 underlined loci only. Within population $F_{I S}$ is the multilocus estimate of Wright's

inbreeding coefficient (calculated for the 25 underlined loci only). 
FIGURE 1. Map of the six sampled locations: SB - Mousterlin, France $\left(47^{\circ} 50^{\prime} 27.4^{\prime \prime} \mathrm{N}, 4^{\circ} 02^{\prime} 18.1^{\prime \prime} \mathrm{W}\right)$, NB - Roscoff, France $\left(48^{\circ} 43^{\prime} 41.5^{\prime \prime} \mathrm{N}, 4^{\circ} 00^{\prime} 20.6^{\prime \prime} \mathrm{W}\right), \mathrm{PDC}-$ Audresselles, France $\left(50^{\circ} 49^{\prime} 27.8^{\prime \prime} \mathrm{N}, 1^{\circ} 35^{\prime} 40.9^{\prime \prime} \mathrm{E}\right)$, DEN - Ebeltoft, Denmark $\left(56^{\circ} 10^{\prime} 04.5^{\prime \prime} \mathrm{N}, 10^{\circ} 43^{\prime} 51.2^{\prime \prime} \mathrm{E}\right)$, SWE - Tjarno, Sweden $\left(58^{\circ} 52^{\prime} 31.9^{\prime \prime} \mathrm{N}\right.$,

$\left.11^{\circ} 06^{\prime} 12.6^{\prime \prime} \mathrm{E}\right)$, NOR - Ny-Alesund, Spitsbergen, Norway $\left(78^{\circ} 55^{\prime} 30^{\prime \prime} \mathrm{N}, 11^{\circ} 55^{\prime} 20^{\prime \prime} \mathrm{E}\right)$.
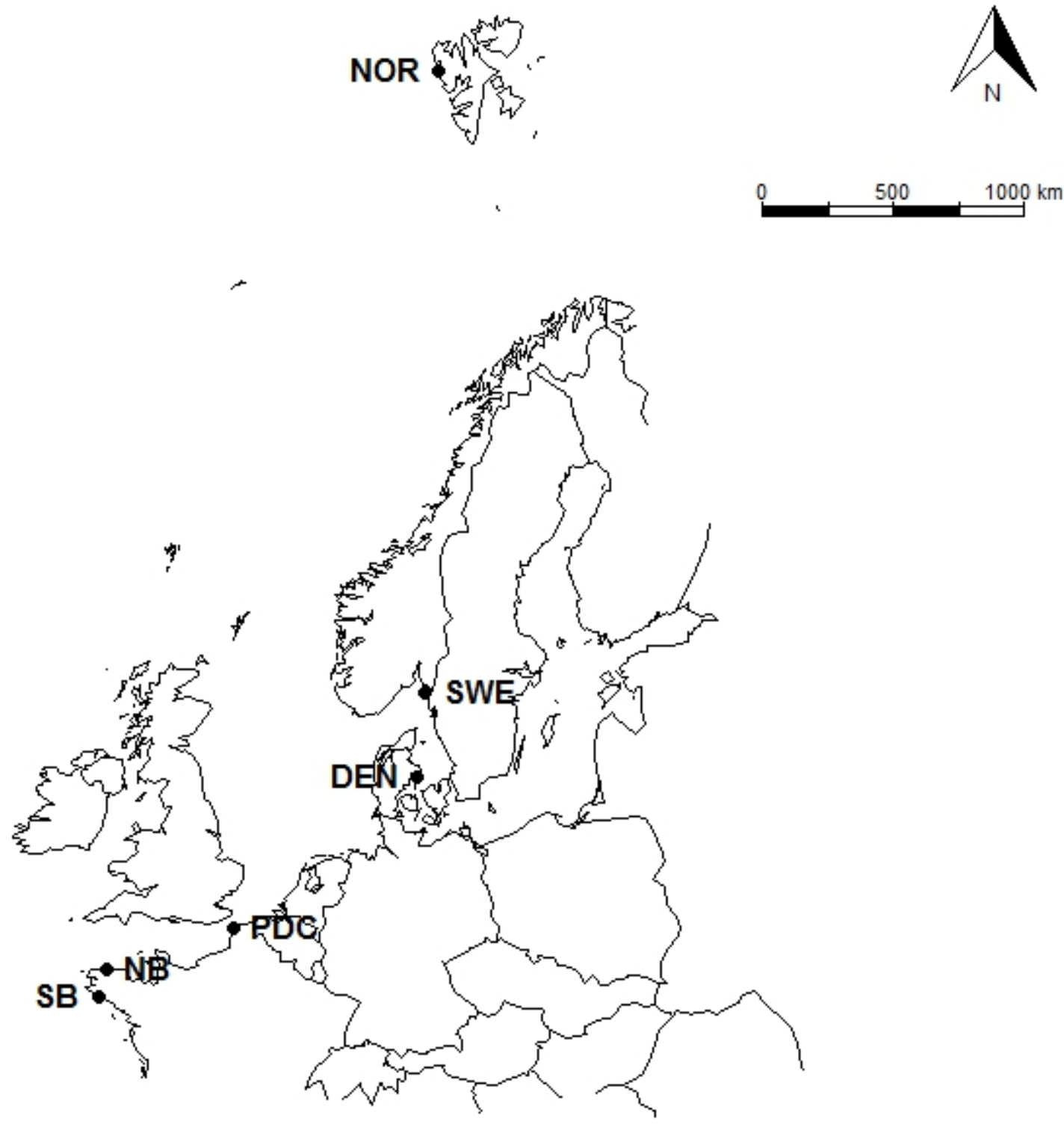
FIGURE 2. Allelic richness (Ar) (filled symbol - left hand side y-axis) and within-population gene diversity $\left(H_{s}\right)$ (open symbol - right hand side $y$-axis) averaged over 25 EST-SSR loci for each of the six sampling localities (16 individuals per population) ordered by latitude. Error bars indicate standard error.

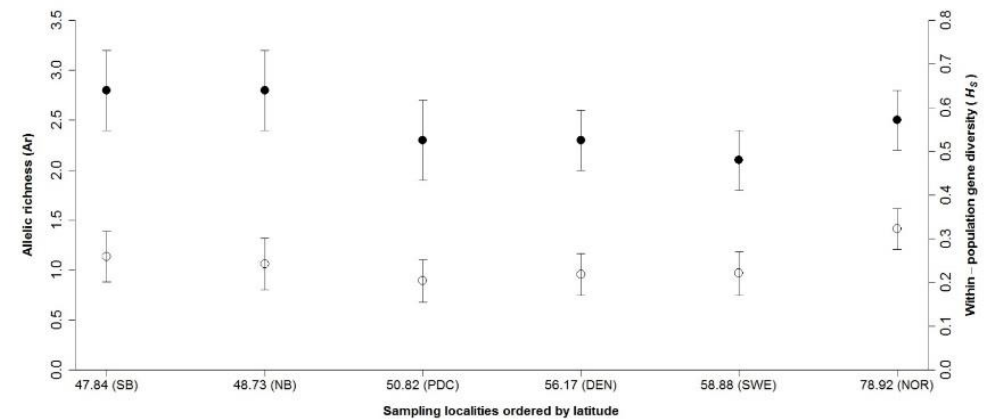


FIGURE 3. Genetic estimates of pairwise differentiation $\left(F_{S T} /\left(1-F_{S T}\right)\right)$ plotted against geographic distance (as the crow flies) for the six sampling localities.

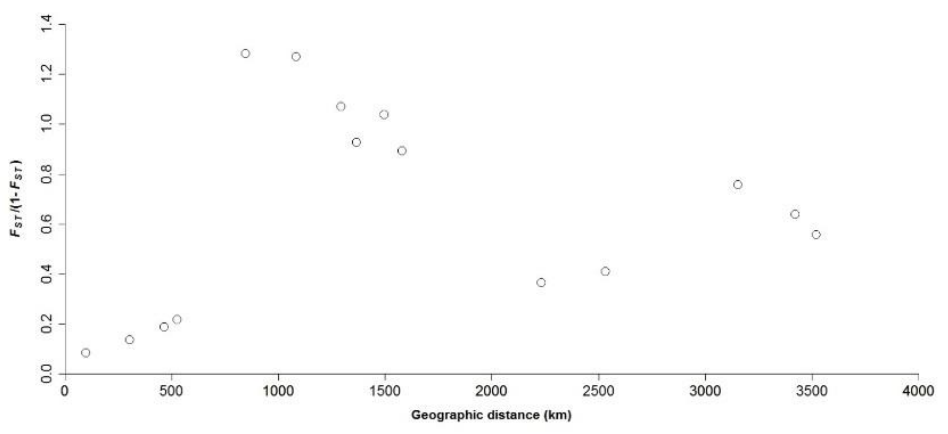


FIGURE 4. Scatterplot of the A) first two components (axes 1 and 2), and B) of the first and third components (axes 1 and 3 ), of the discriminant analysis of principal components (DAPC) performed on $96 \mathrm{~S}$. latissima sporophytes amplified at 25 microsatellite loci, using sampling location as prior clusters. Sampling groups are shown by different colours and inertia ellipses, and each point corresponds to a single individual. C) Membership probability of each S. latissima individual to each of the six sampling localities (differentiated by colour). Individuals are represented by vertical bars. Each individual's sampling locality (i.e. population of origin) is specified along the $\mathrm{x}$-axis.

A)

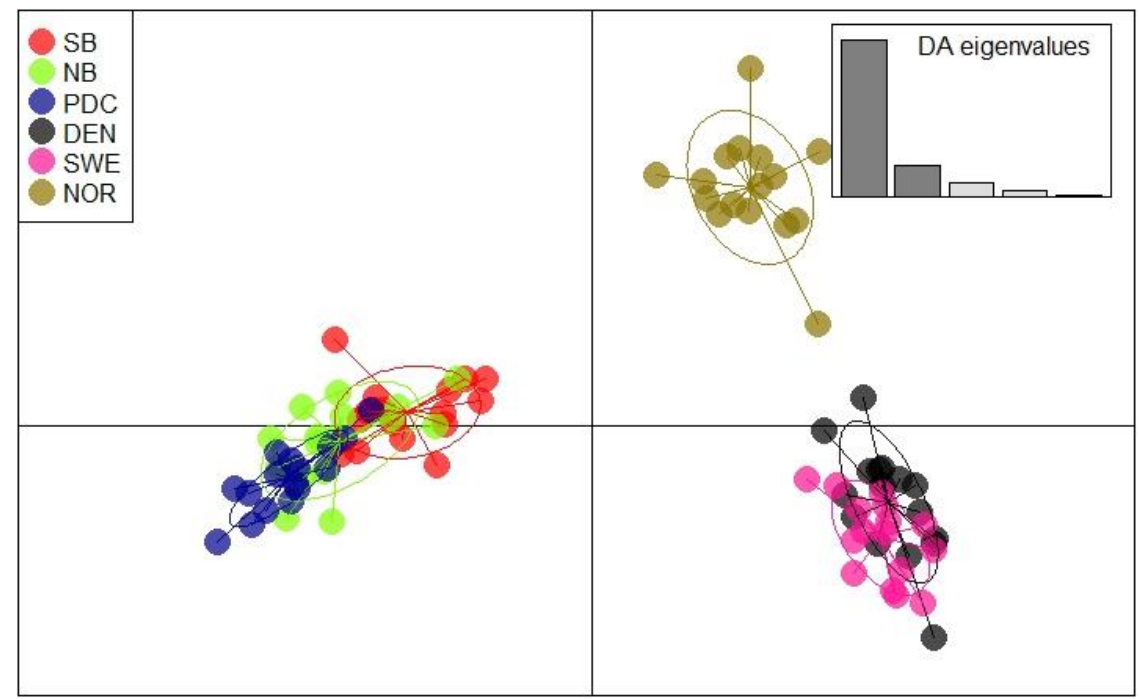

B)

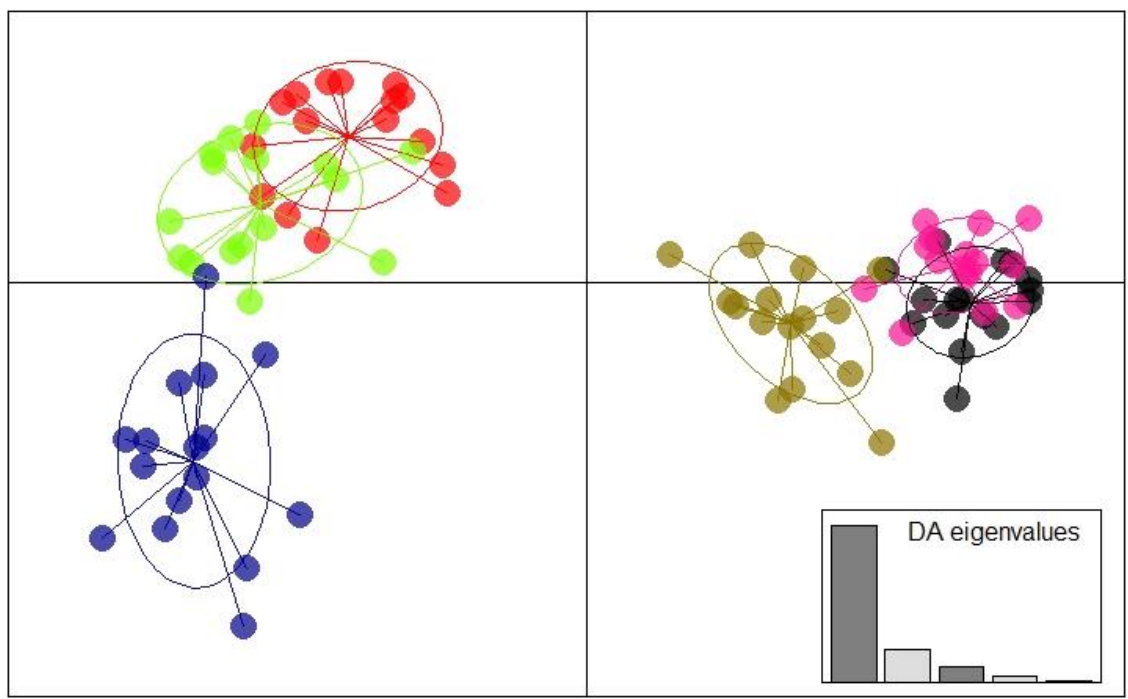

C)

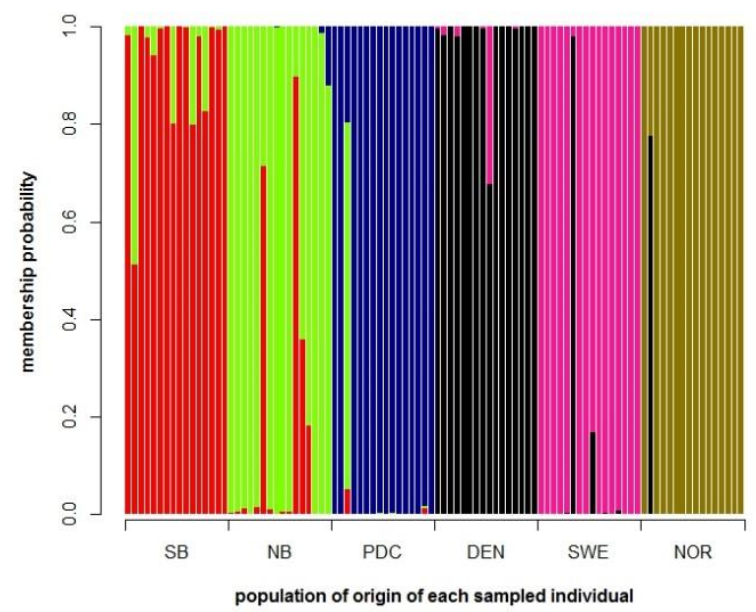


SUPPLEMENTARY FIGURE 1. Comparison of the success of amplification of the EST-SSR loci with different repeat types in the test set of 96 loci.

\section{Comparison of positive amplification betweed different motifs}

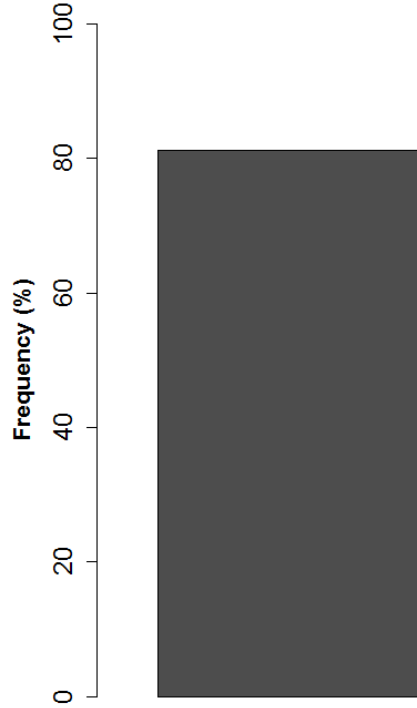

$\mathrm{Di}$

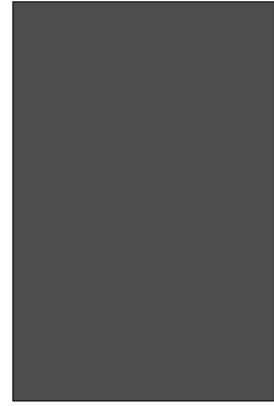

Tri

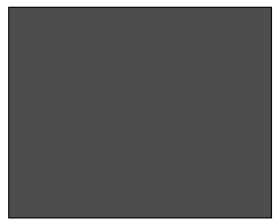

Tetra

otif type

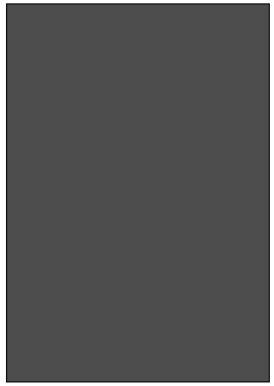

Penta

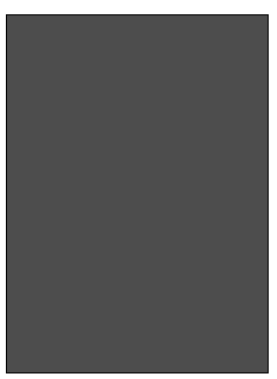

Total 
SUPPLEMENTARY MATERIAL 1. Justification for removal of seven EST-SSR loci from the panel of 32 polymorphic loci listed in Table 2.

Locus Sacl-06 was removed because it exhibited significant null allele frequency within PDC, DEN, and SWE, and significantly positive $F_{I S}$ (i.e. heterozygote deficit) in two of these three populations. Locus Sacl-09 was removed because it exhibited significantly negative $F_{I S}$ (i.e. heterozygote excess) in DEN and SWE and highly negative "All Pops" $F_{I S}$ (in fact the most negative "All Pops" $F_{I S}$ of any the 32 loci-Supplementary Table 3). Additionally, the allelic patterns for this locus in these two populations were odd due to the fact that 15 of the 16 DEN samples and 13 of the 16 SWE samples were heterozygous for the same two alleles. Sacl-27 also exhibited a strange allelic pattern because, despite having five alleles in SB, all $16 \mathrm{SB}$ individuals were homozygous (thus significantly positive $F_{I S}$ and significant null allele frequency - Supplementary Table 3). In the remaining five populations this locus was monomorphic for the same allele. Locus Sacl-47 was removed because within SB it exhibited significantly positive $F_{I S}$ and significant null allele frequency, and within the other five populations it displayed low levels of polymorphism (Supplementary Table 3). For locus Sacl-49, as with Sacl-09, the "All Pops" $F_{I S}$ was highly negative, and its $F_{I S}$ was significantly negative within DEN and SWE. For Sacl-88, there was significant null allele frequency within DEN (no heterozygotes despite this locus possessing two alleles within that population), and this locus was monomorphic or displayed low levels of polymorphism within the other five localities. Lastly, locus Sacl-90 displayed significantly positive $F_{I S}$ and significant null allele frequency within two of the six localities (DEN and SWE), and was thus removed. Significant null allele frequency and/or significantly positive $F_{I S}$ was also detected for several other loci, such as Sacl-24, Sacl-54, or Sacl-65 (Supplementary Table 3). However, as in each of those cases these problems were only observed for a single population, and the loci in question were highly polymorphic and/or showed high levels of $F_{S T}$, we nonetheless retained those loci for the population genetics analyses. Note that, although the seven loci that were removed were deemed unsuitable for our analyses, they could be of use for other types of studies or 
studies on other populations of S. latissima, thus they are also reported in this manuscript and were optimized as part of the multiplexes specified in Table 2 